DHAXNA SOTHIESON

\title{
MARINE PROTECTED AREAS IN THE NORTH-EAST ATLANTIC OCEAN AND SOUTHERN OCEAN: \\ THE ROLE OF REGIONAL ORGANISATIONS IN AREAS BEYOND NATIONAL JURISDICTION
}

Submitted for the LLB (Honours) Degree

Faculty of Law

Victoria University of Wellington

2014 
The international community has recognised Marine Protected Areas (MPAs) as an important tool for area-based management of ecosystems. Regional organisations have taken the lead in areas beyond national jurisdiction to create MPAs. This paper will compare the issues facing the Commission for the Conservation of Antarctic Marine Living Resources (CCAMLR) and the relevant Antarctic Treaty bodies in the Southern Ocean, to the North-East Atlantic Ocean where the Convention for the Protection of the Marine Environment of the North-East Atlantic (OSPAR) and the North-East Atlantic Fisheries Commission (NEAFC) are the lead bodies. Many of the issues that face each region in designating MPAs differ due to geopolitical differences; resulting in the North-East Atlantic producing more success in designating a network of MPAs. The North-East Atlantic organisations, however, face more difficulties to ensure the comprehensive management of MPAs. As CCAMLR and the Protocol on Environmental Protection to the Antarctic Treaty sit within the Antarctic Treaty System, the potential exists for a better integrated management framework in the Southern Ocean. The themes from both regions will then be put into a wider global context to provide some guidance and identify issues for other regional organisations seeking to establish MPAs in ABNJ.

[Marine protected areas, areas beyond national jurisdiction, regional organisations,

CCAMLR, OSPAR.]

\section{Word count}

The text of this paper (excluding cover page, abstract, table of contents, footnotes and bibliography) is 14,797 words. 


\section{Table of Contents}

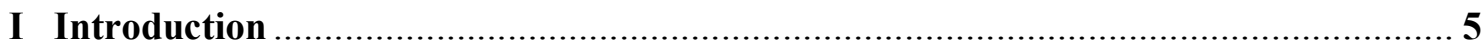

II Marine Protected Areas: A Snapshot of the Global Situation ................................. 6

A Vulnerability of the Oceans and MPAs as a Potential Tool................................. 6

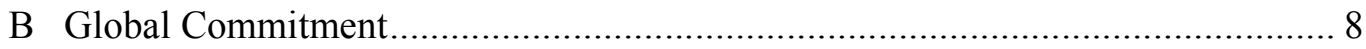

C Legal Foundation and Challenges............................................................ 9

D Importance of Regional Organisations ................................................ 10

III Outline and Progress of the Organisations in the North-East Atlantic and Southern

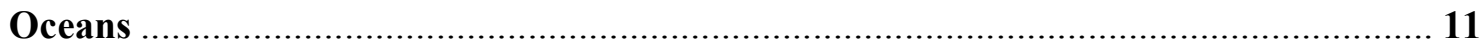

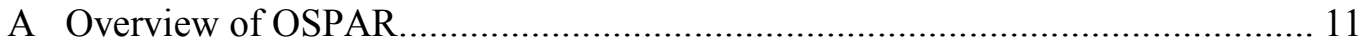

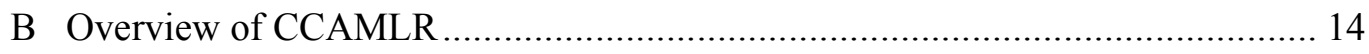

IV Issues Experienced by Both Regions in Designating MPAs .............................. 17

A Scientific Uncertainty ........................................................................ 17

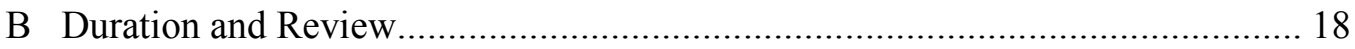

C Competing Interests: Economic versus Conservation ................................. 20

1 South Orkney Islands ............................................................... 22

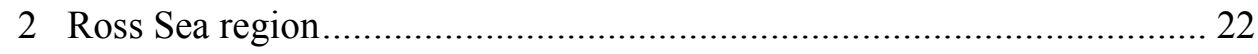

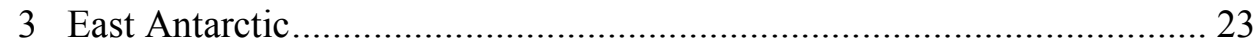

4 How can a balance be achieved? .................................................... 24

D Consensus Voting and Membership Composition ...................................... 24

E Overlapping Extended Continental Shelf Claims........................................ 26

F Why has OSPAR been more successful than CCAMLR? .............................. 28

V Challenges Facing Both Regions in Managing MPAs ...................................... 29

A Institutional Overlap: NEAFC's Role................................................... 30 


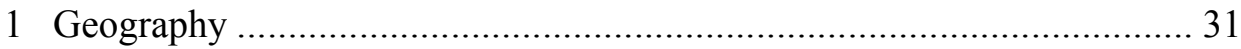

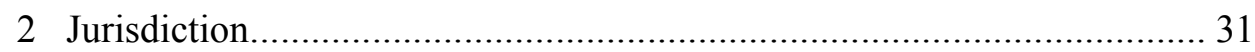

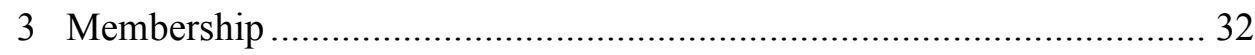

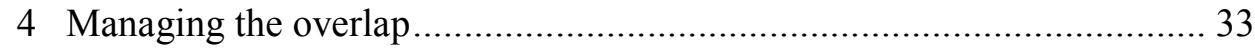

B Potential for an Integrated Approach in the Southern Ocean ..................................... 37

1 Overlap between CCAMLR and the Environment Protocol...................... 38

2 Creation of Protected Areas under the Environment Protocol .................... 39

3 Management of the overlap ………….................................................... 41

C Are Southern Ocean Organisations in a Better Position to Manage Activities? ....... 44

VI The Role of RFMOs for Compliance and Enforcement …….................................. 45

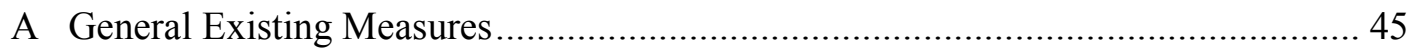

B The Problem of Non-Parties: Is there an Enforcement Right? ................................... 46

VII Guidance and Issues for Other Regional Organisations ……………………….....48

A Other Regional Efforts and Trends ..................................................................... 49

B Are RFMOs or RSCs the Best Forum? ................................................................. 49

C Importance of Institutional Overlap for Management Efforts.................................... 51

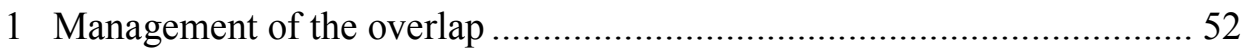

D Limitations of the North-East Atlantic Model …………….................................... 53

1 What if no regional organisations exists? ................................................. 54

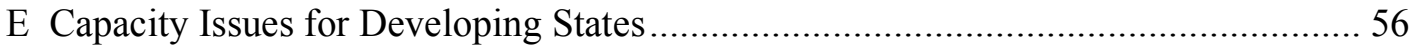

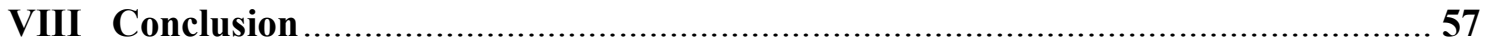

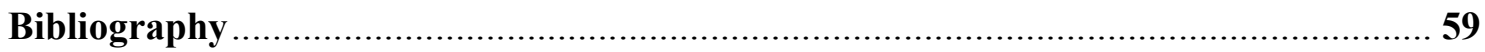




\section{Introduction}

A Marine Protected Area (MPA) is recognised as an effective tool for the protection and conservation of marine biodiversity and habitats. ${ }^{1}$ Many States and organisations have pledged to create a network of representative MPAs over the past thirty years or so. Efforts in areas within national jurisdiction to create MPAs are simpler, as the coastal State retains control and oversight for the designation and management of such areas. The story is different in areas beyond national jurisdiction $(\mathrm{ABNJ})$.

Regional organisations have been the main vehicle to drive designation and management efforts of MPAs in ABNJ. Two regional organisations have stood out for their progress. The first high seas MPA was created in 2009 in the South Orkney Islands southern shelf by the Convention for the Conservation of Antarctic Marine Living Resources ${ }^{2}$ (CCAMLR) Commission. The first network of high seas MPAs was created in 2010 by the Oslo-Paris Convention for the Protection of the Marine Environment of the North-East Atlantic $^{3}$ (OSPAR) Commission. Since these important developments, CCAMLR has repeatedly failed to create further MPAs and has not met its goal of creating a representative network by 2012. OSPAR's ABNJ network also has not grown. The purpose of this paper is to examine the issues facing the North-East Atlantic and Southern Oceans for designating and implementing MPAs in ABNJs. The issues highlighted from the comparative analysis will then be put into a global context to provide guidance for other regional organisations. Developments in both regions operate in different contexts, limiting the ability for a direct comparison, however, some similar general themes exist that link the two regions together. Overall, it will be seen that although they are not a perfect mechanism, regional organisations are the best vehicle to create and manage MPAs.

This paper will begin by providing an overview of MPAs, and the operation of OSPAR and CCAMLR as well the broader operational framework that exists in the respective regions.

\footnotetext{
${ }^{1}$ Conserving Marine Biodiversity: Addressing Existing Commitments and Designing Next Steps for Action (The Pew Environment Group, April 2013) at 12.

${ }^{2}$ Convention on the Conservation of Antarctic Marine Living Resources 1329 UNTS 47 (opened for signature 20 May 1980, entered into force 7 April 1982). [CCAMLR].

${ }^{3}$ Convention for the Protection of the Marine Environment of the North-East Atlantic 2354 UNTS 67 (opened for signature 22 September 1992, entered into force 25 March 1998). [OSPAR].
} 
It will then explore why the designation of a network of MPAs in ABNJ has been relatively more successful by OSPAR compared with CCAMLR. Next, implementation issues both organisations face will be examined. This will highlight the importance of cooperation to promote integrated management with organisations in the North-East Atlantic Ocean; and the potential under CCAMLR for an integrated approach with the Antarctic Treaty System. The paper will then look to how efforts from the North-East Atlantic Ocean and Southern Ocean can be used to improve other regional organisation's efforts.

\section{Marine Protected Areas: A Snapshot of the Global Situation}

In this part, an overview of the need to protect the oceans will be established along with why MPAs can be an effective tool. The global commitment towards MPAs will be discussed, as well as the legal challenges in creation and management highlighting the important role of regional organisations.

\section{A Vulnerability of the Oceans and MPAs as a Potential Tool}

The vulnerability of marine ecosystems worldwide is increasing from the impact of human activities ranging from shipping, ocean acidification, overfishing, climate change, and pollution. ${ }^{4}$ For example, more than 75 per cent of the world's fish stocks are reported as fully exploited or overexploited, ${ }^{5}$ and 70 per cent of the world's coral reefs are threatened or destroyed. ${ }^{6}$ If human impacts on marine ecosystems are left unchecked, the resilience of the ocean system to deal with increasing threats and biodiversity loss will be severely affected. ${ }^{7}$ Marine biodiversity is essential for the maintenance of the planet in a condition which supports

\footnotetext{
${ }^{4}$ Alistair Hobday and others "Missing Dimension- Conserving the largest habitat on Earth: protected areas in the pelagic ocean" in Joachim Claudet (ed) Marine Protected Areas: A Multidisciplinary Approach (Cambridge University Press, Cambridge, 2011) at 349.

${ }^{5}$ Rosemary Rayfuse and Robin Warner "Securing a Sustainable Future for the Oceans Beyond National Jurisdiction: The Legal Basis for an Integrated Cross-Sectoral Regime for High Seas Governance for the 21st Century" (2008) 23 IJMCL 399.

${ }^{6}$ Establishing Resilient Marine Protected Areas- Making it Happen (IUCN World Commission on Protected Areas, 2008) at 2.

${ }^{7}$ Colleen Corrigan and Francine Kershaw Working Towards High Seas Marine Protected Areas: Assessment of Progress Made and Recommendations for Collaboration (UNEP World Conservation Monitoring Centre, October 2008) at 27.
} 
human and other life, therefore, conservation is in the interests of the international community. ${ }^{8}$ The question is how this is to be achieved. The law of the sea has traditionally adopted speciesspecific and sectoral approaches to management, thereby ignoring interrelationships between marine issues. ${ }^{9}$ Ecological evidence indicates the importance of coordinated and systematic management of high seas biodiversity, given the interconnected nature of the oceans. ${ }^{10}$

MPAs are considered to be a key tool to achieve some of the goals of an integrated, ecosystem-based management approach. ${ }^{11}$ A well designed and managed MPA can protect nursery and spawning habitats, provide undisturbed control or reference sites that serve as baselines for scientific research, maintain full genetic variation, ensure resilience and sustain evolutionary processes to name a few effects. ${ }^{12}$ MPAs are not the only recognised 'solution', and when used in conjunction with other management tools, such as marine spatial planning and broad area fisheries management, MPAs can be a cornerstone for marine conservation strategies. $^{13}$

MPAs exist in multiple forms, with diverse definitions and objectives. ${ }^{14}$ MPAs have a special status in comparison with the surrounding waters due to their more stringent regulation of one or more human activities, by one or more measures, for one or more purposes. ${ }^{15}$ The International Union for the Conservation of Nature defines a MPA as:

\footnotetext{
${ }^{8}$ Yoshifumi Tanaka The International Law of the Sea (Cambridge University Press, Cambridge, 2012) at 312313.

${ }^{9}$ Yoshifumi Tanaka "Zonal and Integrated Management Approaches to Ocean Governance: Reflections on a Dual Approach in International Law of the Sea” (2004) 19(4) IJMCL 483 at 486.

${ }^{10}$ Natalie Ban and others "Systematic Conservation Planning: A Better Recipe for Managing the High Seas for Biodiversity Conservation and Sustainable Use" (2014) 7(1) Conservation Letters 41 at 42.

${ }^{11}$ Simonetta Fraschetti, Joachim Claudet and Kirsten Grorud-Colvert "Management- Transitioning from singlesector management to ecosystem-based management: what can marine protected areas offer?" in Joachim Claudet (ed) Marine Protected Areas: A Multidisciplinary Approach (Cambridge University Press, Cambridge, 2011) at 12.

${ }^{12}$ IUCN Establishing Resilient Marine Protected Areas- Making it Happen, above n 6, at 3.

${ }^{13}$ At 3 .

${ }^{14}$ At 4.

${ }^{15}$ Erik J. Molenaar and Alex G Oude Elferink "Marine protected areas in areas beyond national jurisdiction: The pioneering efforts under the OSPAR Convention" (2009) 5 Utrecht Law Review 5 at 6.
} 
A clearly defined geographical space, recognised, dedicated and managed, through legal or other effective means, to achieve the long-term conservation of nature with associated ecosystem services and cultural values. ${ }^{16}$

This paper will focus on MPAs created for the purpose of protecting marine biodiversity and ecosystems. MPAs can incorporate a spectrum of management strategies, from no-take areas explicitly closed to fisheries, to no-entry areas, and multiple use areas which prohibit certain activities. ${ }^{17}$ In many regions, economic and political constraints make it impractical to create one single large MPA of sufficient size to support a representative range of viable, selfsustaining populations of all species. ${ }^{18}$ Establishing representative networks of many small to moderately sized MPAs can provide important spatial links needed to maintain ecosystem processes and connectivity, as well as improve resilience by spreading risks to help ensure the long-term sustainability of populations better than single sites. ${ }^{19}$

\section{B Global Commitment}

At the 2002 World Summit on Sustainable Development, participating States agreed to establish a global system of representative MPAs by 2012. ${ }^{20}$ States party to the 1992 Convention on Biological Diversity (CBD) agreed to adopt this approach and develop a strategy to protect at least 10 per cent of the world's ecological regions by $2012 .{ }^{21}$ To date, the global distribution of protected areas is very limited geographically and are generally located close to the Exclusive Economic Zone (EEZ) of the coastal State. ${ }^{22}$ Around 1.31 per cent of the ocean's surface area is designated within MPAs, leading to uneven and patchy ecological

\footnotetext{
${ }^{16} \mathrm{IUCN}$ "When is a Marine Protected Area really a Marine Protected Area" (8 September 2012) $<$ www.iucn.org > . See further the OSPAR definition in OSPAR Recommendation 2003/3 on a Network of Marine Protected Areas (2003), and the CCAMLR definition in CCAMLR Commission Conservation Measure 91-04 General framework for the establishment of CCAMLR Marine Protected Areas (2011).

${ }^{17}$ Simonetta Fraschetti, Joachim Claudet and Kirsten Grorud-Colvert, above n 11, at 23.

${ }^{18}$ IUCN Establishing Resilient Marine Protected Areas- Making it Happen, above n 6, at 10.

19 At 10 .

${ }^{20}$ World Summit on Sustainable Development Plan of Implementation of the World Summit on Sustainable Development, 4 September 2002, A/CONF.199/20 Annex at 32(c).

${ }^{21}$ CBD Seventh Meeting of the Conference of the Parties to the Convention on Biological Diversity (2004) at Decision VII/5 at 19 and Decision VII/30.

${ }^{22}$ Corrigan and Kershaw, above n 7, at 15.
} 
representation. ${ }^{23}$ The distribution of MPAs overlooks the fact that coastal and open ocean marine ecosystems are inter-connected, requiring protection at distances further from the coast. In the absence of a global agreement detailing the requirements to designate and manage MPAs in $\mathrm{ABNJ}$, regional organisations have taken the lead and are at the forefront of developments in the Mediterranean Sea, Sargasso Sea, North-East Atlantic Ocean, and the Southern Ocean. Aside from the Pelagos Sanctuary within the Mediterranean Sea, there are no other MPAs designated in ABNJ. ${ }^{24}$ In 2010, as part of the Aichi Biodiversity Targets, States agreed to extend the CBD deadline of 10 per cent protected coastal and marine areas to $2020 .^{25}$

\section{Legal Foundation and Challenges}

MPAs have a loose legal foundation in ABNJ. There is no express legal basis for their creation and management in any international instrument. The best way to consolidate the legal foundation of MPAs in ABNJs is through a new global agreement. In the absence of such agreement, it can be argued that MPAs are consistent with international law, namely the United Nations Convention on the Law of the Sea (UNCLOS). ${ }^{26}$ The argument for an implicit creation can be found from various articles in the UNCLOS. All States are under a general obligation "to protect and preserve the marine environment", arising from customary international law and restated in Article 192. ${ }^{27}$ Further, Article 194(5) requires that those measures taken to protect and preserve the marine environment "shall include those necessary to protect and preserve rare or fragile ecosystems as well as the habitat of depleted, threatened or endangered species and other forms of marine life". ${ }^{28}$

These conservation obligations compete with and need to be balanced against the freedom of the high seas, in particular freedom of fishing and navigation. These freedoms,

\footnotetext{
${ }^{23}$ Mark Spalding and others "Protecting Marine Spaces: Global Targets and Changing Approaches" (2013) 27 Ocean Yearbook 213 at 218.

${ }^{24}$ Note that the Pelagos Sanctuary is only potentially located in the high seas as the Mediterranean States have not declared their Exclusive Economic Zones.

${ }^{25}$ CBD Tenth Meeting of the Conference of the Parties to the Convention on Biological Diversity (2010) at Decision X/2 Annex.

${ }^{26}$ United Nations Convention on the Law of the Sea 1833 UNTS 3 (opened for signature 10 December 1982, entered into force 16 November 1994). [UNCLOS].

27 Tullio Scovazzi "Marine Protected Areas on the High Seas: Some Legal and Policy Considerations" (2004) 19(1) IJMCL 1 at 5.

${ }^{28}$ Article 194(5).
} 
however, are not absolute. The tension between the two can explain some of the difficulties States face in agreeing to designate MPAs through regional organisations, as fisheries freedoms tend to prevail over the conservation objectives. A further legal challenge is the principle of exclusive flag State jurisdiction, a governing principle in ABNJ, as the high seas are beyond the general jurisdiction of any State or organisation. ${ }^{29}$ The content of flag States duties is twofold. $^{30}$ First, States have a duty to cooperate in both the protection of the marine environment, and the conservation and management of high seas living resources. ${ }^{31}$ Second, States have a duty to effectively control vessels flying its flag. Cooperation between States is vital in $\mathrm{ABNJ}$ to agree to conservation measures, however the freedom of fishing can be an impediment to MPA negotiations. ${ }^{32}$ A lack of effective implementation of flag State's jurisdiction over its fishing vessels, often due to the lack of will and the capability to properly regulate fishing activities, can further undermine conservation objectives. ${ }^{33}$

\section{Importance of Regional Organisations}

As the living resources of ABNJ are not subject to State claims, States must create MPAs through regional and international organisations rather than unilaterally. Regional organisations have been the main driver of such efforts, given that no international agreement exists (and thereby any international organisation) that positively recognises the creation of MPAs in ABNJ. Depending on the convention text, it is likely some legal basis exists to create MPAs, but this will only bind parties to that particular organisation. Two types of regional organisations can be effective in the creation of MPAs; these are Regional Seas Conventions (RSCs) or similar agreements, and Regional Fisheries Management Organisations (RFMOs). RSCs are agreements, generally with accompanying action plans, established by groups of

${ }^{29}$ Stuart Kaye "Implementing high seas biodiversity conservation: global geopolitical considerations" (2004) 28(3) Marine Policy 221 at 221.

${ }^{30}$ Rosemary Rayfuse "The Anthropocene, Autopoiesis and the Disingenuousness of the Genuine Link: Addressing Enforcement Gaps in the Legal Regime for Areas Beyond National Jurisdiction" in Erik J Molenaar and Alex Oude Elferink (eds) The International Legal Regime of Areas Beyond National Jurisdiction: Current and Future Developments (Martinus Nijhoff Publishers, Leiden, 2010) at 176.

${ }^{31}$ UNCLOS Articles 117, 118 and 197.

${ }^{32}$ Scovazzi "Marine Protected Areas on the High Seas: Some Legal and Policy Considerations", above n 27, at 6. See also the International Tribunal for the Law of the Sea decision in The MOX Plant Case (Ireland $v$ United Kingdom), Provisional Measures where the Tribunal said "the duty to cooperate is a fundamental principle in the prevention of pollution of the marine environment under Part XII of the Convention and general international law".

${ }^{33}$ Tanaka The International Law of the Sea, above n 8, at 242. 
countries sharing common seas. ${ }^{34}$ RSCs that were originally heavily focused on pollution have either been amended or have adopted additional instruments to incorporate new principles of ecosystem based-management and the conservation of marine biodiversity. ${ }^{35}$ The downfall is that most of these agreements are limited in their coverage of $\mathrm{ABNJ}$, with scope only to regulate activities within 200 nautical miles to the coast. ${ }^{36}$ Further, fisheries management is usually considered separate from the environmental protection mandates found in RSCs; CCAMLR is the exception not the rule in this regard. RFMOs have been developed to manage and conserve high seas fish stocks, as well as straddling and highly migratory fish stocks in some but not all regions. ${ }^{37}$ RFMOs have made some progress towards reversing the impacts of over-fishing, but many are focused on single-species fisheries management and few have taken proactive measures to protect ecologically significant areas, or reduce bycatch of vulnerable species. ${ }^{38} \mathrm{~A}$ number of RFMOs have established defined areas on the high seas that are closed to some or all types of fisheries, thus affording protection to other species and ecosystems within the area. $^{39}$

\section{Outline and Progress of the Organisations in the North-East Atlantic and}

\section{Southern Oceans}

To understand the context of the issues facing each region, a brief overview will be provided in this section of OSPAR and CCAMLR, and the progress made in these regions to designate and manage MPAs.

\section{A Overview of OSPAR}

OSPAR is an example of a RSC that seeks to regulate activities that can have adverse effects on the ecosystems and the biodiversity in the North-East Atlantic. ${ }^{40}$ The OSPAR maritime area notably includes a large area, around 40 per cent, beyond the jurisdiction of

\footnotetext{
${ }^{34}$ Corrigan and Kershaw, above $\mathrm{n} 7$, at 13 .

35 Spalding and others, above n 23, at 217.

${ }^{36}$ Corrigan and Kershaw, above $\mathrm{n} 7$, at 13.

37 At 12.

${ }^{38}$ Lora Nordtvedt Reeve, Anna Rulska-Domino and Kristina M. Gjerde "The Future of High Seas Marine Protected Areas" (2012) 26 Ocean Yearbook 265 at 274.

${ }^{39}$ Corrigan and Kershaw, above n 7, at 12 and 13.

${ }^{40}$ OSPAR Annex V, Article 2.
} 
coastal States. Five large marine areas comprise OSPAR's convention area; the Arctic waters, the greater North Sea, the Celtic Seas, the Bay of Biscay and Iberian Coast, and the Wider Atlantic. The MPAs in ABNJ designated are in the Wider Atlantic region.

Two major exceptions exist to OSPAR's general jurisdiction to regulate activities, with fisheries management and certain limitations for the regulation of shipping falling outside the Convention's scope.$^{41}$ These limitations require that the OSPAR Commission cooperates with the other international organisations that have competence in the same area. Indeed, the Commission has undertaken cooperation efforts with the North-East Atlantic Fisheries Commission (NEAFC), the International Maritime Organisation (IMO), and the International Seabed Authority (ISA).

The 2003 Bremen Ministerial Declaration by the OSPAR parties sought to establish an ecologically coherent network of well-managed MPAs by 2010, including within ABNJ. ${ }^{42}$ The following MPAs in ABNJ form a network of sites covering representative areas of the different biogeographic regions and provinces of the Wider Atlantic. ${ }^{43}$ These sites aim to protect a series of seamounts, sections of the Mid-Atlantic Ridge which contains unique processes and organisms, and range of vulnerable deep-seabed habitats and species. ${ }^{44}$ The MPAs were designated in 2010, and constitute a combined area of 465,165 square kilometers, around eight per cent of OSPAR's waters beyond 200 nautical miles:

- Charlie-Gibbs South MPA.

- Milne Seamount Complex MPA.

- Mid-Atlantic Ridge north of the Azores High Seas MPA.

- Altair Seamount High Seas MPA.

- Antialtair Seamount High Seas MPA.

- Josephine Seamount Complex High Seas MPA.

- Charlie-Gibbs North High Seas MPA (added in 2012).

\footnotetext{
${ }^{41}$ OSPAR Annex V, Article 4. Molenaar and Oude Elferink "Marine protected areas in areas beyond national jurisdiction: The pioneering efforts under the OSPAR Convention", above n 15, at 14.

42 OSPAR Commission 2012 Status Report on the OSPAR Network of Marine Protected Areas (2013) at 8.

43 At 21.

${ }^{44}$ Yoshifumi Tanaka "Reflections on High Seas Marine Protected Areas: A Comparative Analysis of the Mediterranean and the North-East Atlantic Models" (2012) 81 Nordic Journal of International Law 295 at 310.
} 


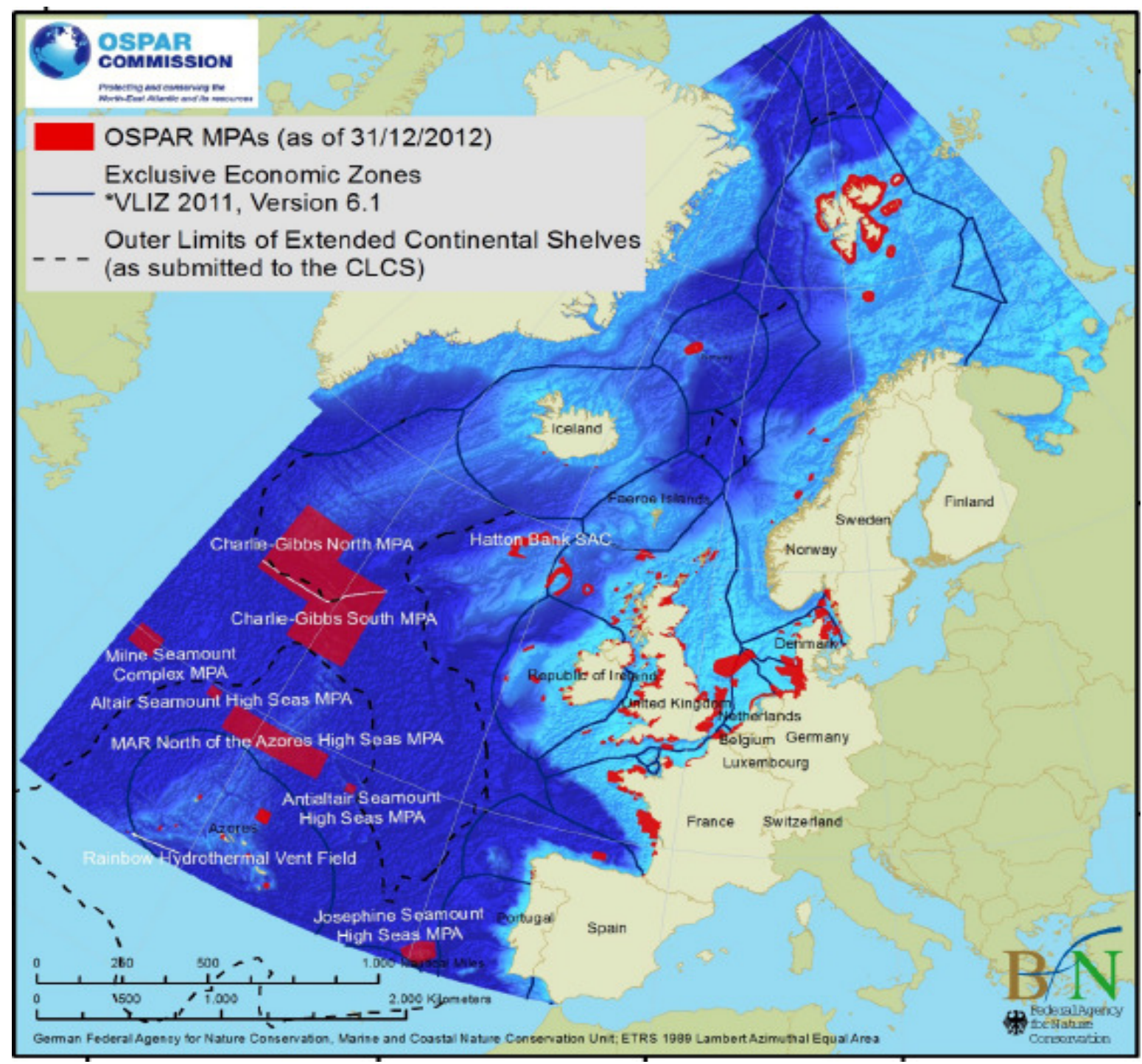

Some management provisions are contained in OSPAR Recommendations for each of these areas including awareness raising and information building; however, to date no crosssectoral management plans have been put in place. ${ }^{46}$ In 2010 at Bergen, the parties agreed to ensure that these MPAs would be part of a well-managed network by $2016 .{ }^{47}$

${ }^{45}$ OSPAR Commission 2012 Status Report on the OSPAR Network of Marine Protected Areas, above n 42, at 10.

${ }^{46}$ Robin M. Warner "Conserving marine biodiversity in areas beyond national jurisdiction: co-evolution and interaction with the law of the sea" (2014) 1 Frontiers in Marine Science 1 at 7 and 8.

${ }^{47}$ OSPAR Commission OSPAR Recommendation 2010/2 on amending Recommendation 2003/3 on a network of Marine Protected Areas (2010) at [2.2]. 
CCAMLR is an important part of the Antarctic Treaty System (ATS). It is one of the constituent agreements signed by the Antarctic Treaty Consultative Parties (ATCP) to the Antarctic Treaty. ${ }^{48}$ The catalyst for the Convention was the realisation that conserving Antarctic krill, regarded as a keystone species of the Southern Ocean, was fundamental to maintaining the Antarctic marine ecosystem. ${ }^{49}$ The Convention established a regulatory Commission and scientific advisory body (SC-CAMLR). CCAMLR is a unique treaty as it arose from the belief that the whole Southern Ocean ecosystem is interlinked; distinguishing it from other multilateral fisheries conventions and RSCs as it has a mandate to conserve the ecosystem and to regulate all fishing activities. ${ }^{50}$

The 1991 Protocol on Environmental Protection to the Antarctic Treaty (Environment Protocol), one of the other constituent agreements of the ATS, established the Committee on Environmental Protection (CEP). The CEP plays an advisory role to the ATCP to help implement the Protocol. CCAMLR and the Environment Protocol's mandate to protect the marine environment overlaps as the Protocol also allows for the creation of protected areas with a marine component. ${ }^{51}$ As a result of discussions between the two bodies, CCAMLR will take the lead in relation to MPAs, ${ }^{52}$ although this remains an area where better coordination is required.

CCAMLR had its first MPA workshop in 2005. With the aid of the bioregionalisation programme, CCAMLR has identified nine planning domains, seen below, as a basis for future

\footnotetext{
48 Antarctic Treaty 402 UNTS 71 (opened for signature 1 December 1959, entered into force 23 June 1961). The other agreements are the Convention on the Conservation of Antarctic Seals of 1972, the Convention on the Regulation of Antarctic Mineral Resource Activities 1988, and the 1991 Protocol on Environmental Protection to the Antarctic Treaty.

${ }^{49}$ Denzil Miller, Eugene Sabourenkov and David Ramm "Managing Antarctic Marine Living Resources: The CCAMLR Approach" (2004) 19(3) IJMCL 317 at 319.

${ }^{50}$ Karl-Hermann Kock (ed) “Understanding CCAMLR's Approach to Management” (2000) at 7.

${ }^{51}$ Adriana Fabra and Virginia Gascon "The Convention on the Conservation of Antarctic Marine Living

Resources (CCAMLR) and the Ecosystem Approach” (2008) 23 IJMCL 567 at 573 at 585.

${ }^{52}$ Report of the Joint CEP/SC-CAMLR Workshop (CEP 11, April 2009) at [7.7].
} 
MPAs. ${ }^{53}$ In 2009, CCAMLR set 2012 as a target for establishing a network of MPAs. ${ }^{54}$ To date, only one such MPA has been created.

Figure 2 CCAMLR Planning Domains ${ }^{55}$

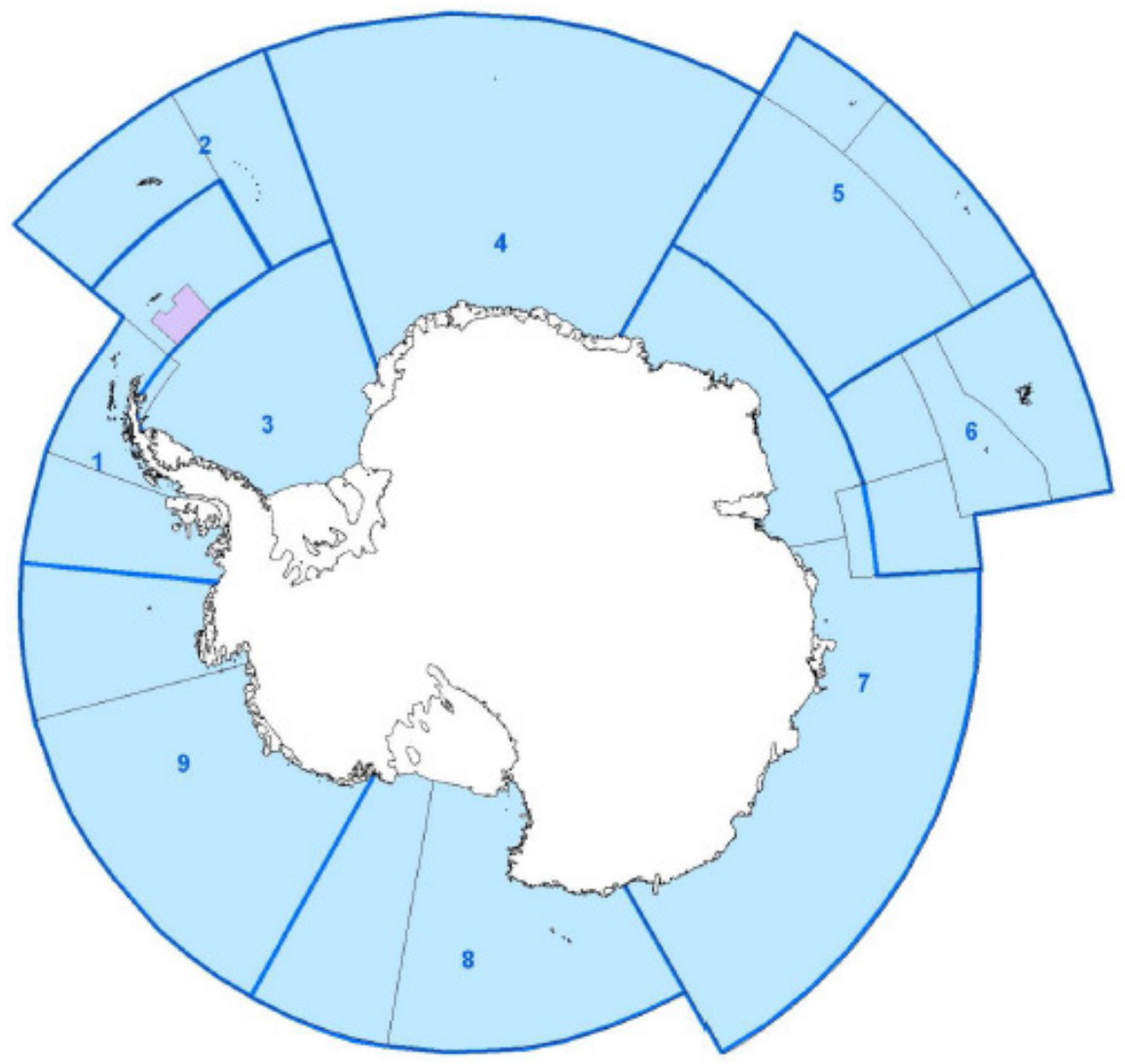

Planning domains defined by the Workshop to provide an updated mechanism by which to plan and report on the development of MPAs across the Convention Area. (1: Western Antarctic PeninsulaSouth Scotia Arc; 2: North Scotia Arc; 3: Weddell Sea; 4: Bouvet-Maud; 5: del Cano-Crozet; 6: Kerguelen Plateau; 7: East Antarctica; 8: Ross Sea region; 9: Amundsen-Bellingshausen.) Planning domain boundaries (thick lines) follow subarea boundaries (thin lines) where possible. The existing South Orkney Islands southem shelf MPA (shaded) is also shown.

The South Orkney Islands MPA, created in 2009, is intended to be the first step towards a representative network of MPAs within the Southern Ocean. ${ }^{56}$ It covers just under 94,000

${ }^{53}$ Karen Scott "Conservation on the High Seas: Developing the Concept of the High Seas Marine Protected Areas" (2012) 27 IJMCL 849 at 852.

${ }^{54}$ CCAMLR Commission Report of the Twenty-Eight Meeting of the Commission, October-November 2009, CCAMLR-XXVIII at [7.19].

${ }^{55}$ Annex 6 of the Report of the Workshop on Marine Protected Areas (August-September 2011) at 296 in Scientific Committee for the Conservation of Antarctic Marine Living Resources Report of the Thirtieth Meeting of the Scientific Committee, October 2011, SC-CAMLR-XXX.

${ }^{56}$ CCAMLR Commission Report of the Twenty-Eight Meeting of the Commission, above n 54, at [7.10]. 
square kilometers of area on the high seas, about 0.5 per cent of the Convention area. ${ }^{57}$ All types of fishing activities are prohibited within the defined area, with the exception of some scientific fishing research activities. ${ }^{58}$ No discharges, no dumping of any type of waste, and no transshipment activities by any fishing vessel can take place within the defined area. ${ }^{59}$ This affords the area an extremely high level of protection.

Figure 3 Ross Sea and East Antarctic Proposals ${ }^{60}$

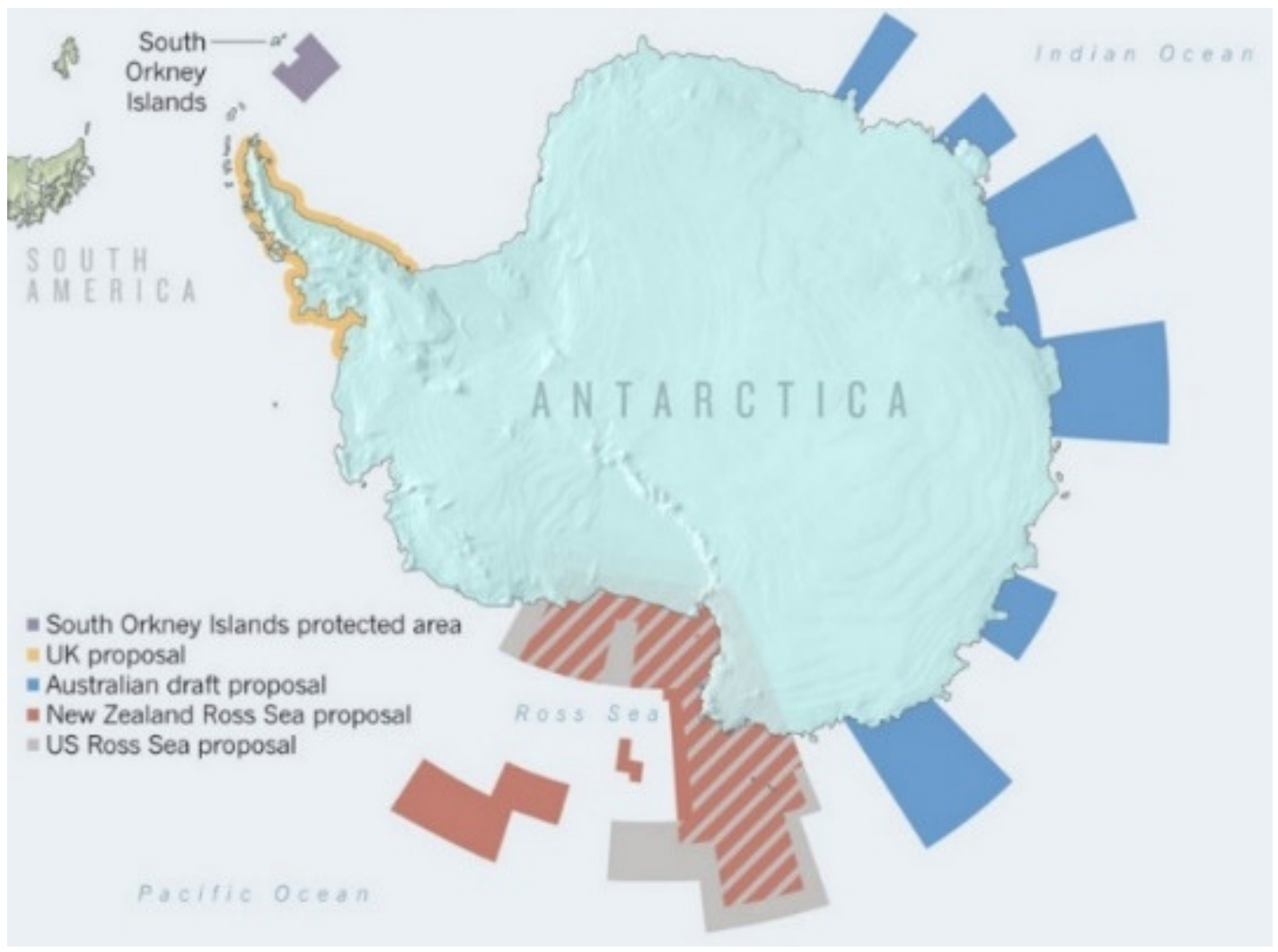

The CCAMLR Commission has since failed to create any further MPAs. The most recent proposals were for the creation of the Ross Sea and East Antarctica regions, shown in the figure above. The Ross Sea proposal is the most ambitious MPA yet, and at the initially proposed time, aimed to establish the world's largest marine reserve. Both proposals have been

\footnotetext{
${ }^{57}$ Scott "Conservation on the High Seas: Developing the Concept of the High Seas Marine Protected Areas", above $n$ 53, at 852 .

${ }^{58}$ CCAMLR Commission Conservation Measure 91-03 Protection of the South Orkney Islands southern shelf (2009) at [1].

${ }^{59}$ At [3] and [4].

${ }^{60}$ Daniel Cressey "Disappointment as Antarctic protection bid fails" (1 November 2013) nature international weekly journal of science $<$ www.nature.com $>$.
} 
blocked three times. Russia, Ukraine, and China voted against the creation of the Ross Sea MPA at the last Commission meeting in October-November 2013, even after the proposed reserve was scaled back from 2.27 to 1.34 million square kilometers. ${ }^{61}$

\section{Issues Experienced by Both Regions in Designating MPAs}

A number of factors explain why OSPAR has been more successful than CCAMLR in designating a representative network of MPAs in $\mathrm{ABNJ}$, these will be explored in this section. The ability to create MPAs is found in Article IX 2(g) of CCAMLR which allows for the establishment of closed areas for the purpose of scientific study or conservation. ${ }^{62}$ The OSPAR Convention does not explicitly refer to closing areas, but allows "necessary measures" to be undertaken in relation to "specific areas or sites". ${ }^{63}$ Both organisations require some level of scientific support for the sites which can operate as a double-edged sword.

\section{A Scientific Uncertainty}

Marine life and ecosystems in ABNJ have historically been understudied, due to the distance and associated difficulties in doing so. ${ }^{64}$ The existence of scientific uncertainty, in terms of sufficiency of research to support MPA proposals and monitoring plans, can be a barrier for the designation of MPAs. Both organisations have a list of criteria for site selection and scientific experts advising them. There is, however, no consistent criteria that each organisation uses and gaining political support for data-poor regions can be problematic. Requiring some scientific basis for a MPA may result in sites being chosen because they are better studied at the expense of those sites with poor data but still in need of protection. ${ }^{65}$

Both organisations have made attempts to apply the precautionary approach with varying degrees of success. The Milne Seamount complex, one of the OSPAR MPAs, is protected largely on the basis of inferred importance to biodiversity from similar habitats and

\footnotetext{
${ }^{61}$ Jamie Morton "NZ marine reserve bid blocked" The New Zealand Herald (online ed, 1 November 2013).

${ }^{62}$ CCAMLR Article IX (2)(g).

${ }^{63}$ OSPAR Articles 2(1)(a) and 3(1)(b)(ii).

${ }^{64}$ Reeve, Rulska-Domino and Gjerde "The Future of High Seas Marine Protected Areas", above n 38, at 268.

${ }^{65}$ B.C. O'Leary and others "The first network of marine protected areas (MPAs) in the high seas: The process, the challenges and where next" (2012) 36 Marine Policy 598 at 600.
} 
places around the Wider Atlantic Ocean. ${ }^{66}$ Whereas some States have stalled progress on the East Antarctic MPA proposal, requesting more detail. The proposed East Antarctic area is considered to be "data-poor" with large ecological uncertainties existing in the region. ${ }^{67}$ Regardless, the precautionary approach guided the design of the seven representative MPAs jointly sponsored by Australia and France. ${ }^{68}$ Some CCAMLR members have stated that the proposed conservation objectives are too general and subject to uncertainty, "requiring more precision particularly in relation to the scientific basis of the proposal". ${ }^{69}$ Although the proposal is based on the best scientific advice available, ${ }^{70}$ Ukraine wished to designate small special research areas to obtain more targeted scientific data. ${ }^{71} \mathrm{~A}$ balance must be struck between having an adequate scientific foundation to make a MPA politically sustainable and operative on the one hand, but on the other hand to ensure a lack of research of an area with apparent importance is not omitted protection. Both organisations have had different successes in applying the precautionary approach highlighting that political will is imperative to designate data-poor MPAs, heightened by the consideration that most regions in ABNJ are scantily studied.

\section{B Duration and Review}

At the Special Meeting of the CCAMLR Commission, Japan raised as an issue the duration of a MPA designation. It insisted that a MPA measure must have a procedure to lapse it after a certain period of designation (known as a "sunset clause"), unless it is proved that the MPA is sufficiently well functioning. ${ }^{72}$ Norway expressly agreed with the position of Japan on the usefulness of such a sunset clause. ${ }^{73}$ Currently, Conservation Measure 91-04 requires periodic reviews to be conducted every 10 years, at which time the MPA can be modified

\footnotetext{
${ }^{66}$ At 600 .

${ }^{67}$ Cassandra M. Brooks "Competing values on the Antarctic high seas: CCAMLR and the challenge of marineprotected areas" (2013) 3(2) The Polar Journal 277 at 286.

${ }^{68}$ The proposed MPAs would conserve areas in the high latitudes of the Indian sector of the Southern Ocean in the following areas- Gunnerus, Enderby, MacRobertson, Prydz, Drygalski, Wilkes, and D’Urville Sea-Mertz.

${ }^{69}$ CCAMLR Commission Report of the Thirty-Second Meeting of the Commission, October-November 2013, CCAMLR-XXXII at [7.25].

${ }^{70}$ Scientific Committee for the Conservation of Antarctic Marine Living Resources Report of the First Intersessional Meeting of the Scientific Committee, July 2013, SC-CAMLR-IM-I at [2.55].

${ }^{71}$ CCAMLR Commission Report of the Second Special Meeting of the Commission, July 2013, CCAMLR-SMII at [3.69].

72 At [3.35].

${ }^{73}$ At [3.36].
} 
taking into account the results of monitoring activities. The amended Ross Sea proposal by New Zealand and the United States of America (US) at the Special Meeting included a duration provision whereby the CCAMLR Commission can take a decision to reaffirm or modify the MPA, or adopt a new MPA, 50 years after the MPA comes into force. ${ }^{74}$ This essentially could mean a vote to reauthorise or renew the MPA after a certain time period, and if this is unsuccessful the MPA would lapse.

The desire for a sunset clause is similar to the features of the Southern Ocean Sanctuary, established by the International Whaling Commission in 1994, with the Sanctuary subject to a ten year review open for change. During the International Whaling Commission's 2005 meeting, a proposal was made by Japan to remove the sanctuary, but it failed to reach the 75 per cent majority required. ${ }^{75}$ Similarly, efforts to remove protection measures have the potential to dominate in CCAMLR. CCAMLR's Commission operates on a consensus voting basis, not a super majority, potentially allowing one country's objection to the MPA to be sufficient to close it.

The International Union for the Conservation of Nature has labelled CCAMLR member's discussion of such a clause as a "regressive step". ${ }^{76}$ A sunset clause for MPAs is undesirable for a number of reasons. There needs to be a long term commitment to the management of MPAs. To put an expiration on it would undermine the various conservation objectives of a MPA such as establishing resilience and restoring populations. Protected areas should be managed in perpetuity and not as a short-term temporary management strategy. ${ }^{77}$ The effect of having a sunset clause will be likely to perpetuate the same cycle of degradation of the marine environment. There will be little incentive for States to comply with measures if they are only for the short term, thereby undermining the concept of sustainable ecosystems. Further, it is not possible at the time of designation to determine when the MPA will no longer be needed, and this is reflected in the absence of such a sunset clause in widely accepted definitions of MPAs. ${ }^{78}$

\footnotetext{
${ }^{74}$ At [3.11].

75 “Double blow for Japan's whalers" The Guardian (online ed, 22 June 2005).

${ }^{76}$ CCAMLR Commission Report of the Second Special Meeting of the Commission, above n 71, at [3.71].

${ }^{77}$ Antarctic and Southern Ocean Coalition Key Principles in Designating Marine Protected Areas and Marine Reserves submitted to CCAMLR 21 September 2013, CCAMLR-XXXII/BG/16 at 7.

${ }^{78}$ At 7.
} 
MPAs should be flexible through review clauses, but only to allow necessary for management measures and to ensure the MPA is still meeting long-term conservation objectives. ${ }^{79}$ A sunset clause may result in a similar political impasse that plagues the International Whaling Commission, given the economic interests involved in fishing. New Zealand recognised that "a sunset clause is an important issue and to take it off the table would be to undermine the talks" ${ }^{80}$ The CCAMLR Commission has stated that the duration of MPAs, amongst other issues, will make it difficult for States to reach a consensus for further negotiations of the Ross Sea and East Antarctic MPAs. ${ }^{81}$ The idea of a MPA with an expiration date ventures into unchartered waters. Leaving this issue on the table can undermine the purpose of the MPA to meet its long term conservation objectives.

\section{Competing Interests: Economic versus Conservation}

For OSPAR, one of the factors aiding the application of the precautionary approach is the lack of significant economic activity in the designated areas. ${ }^{82}$ Fisheries activities occur closer to the coastal States and in the other four regions of the OSPAR maritime area such as the Arctic waters. ${ }^{83}$ The current MPAs seek largely to protect seamounts, hydrothermal vents, and the unique ecology around the Mid-Atlantic Ridge. The sole aim was not to restrict fisheries activities, as the major threats to these habitats/ecosystems come also from marine scientific research and tourism. CCAMLR is in a different position.

Article II(1) of the CCAMLR affirms that "the objective of this Convention is the conservation of Antarctic marine living resources" and continues to state "for the purposes of the Convention, the term 'conservation' includes rational use". ${ }^{84}$ Exactly how conservation is to include rational use remains the subject of debate and tension amongst the contracting parties. This tension is common for most RFMOs as member States face competing with the

\footnotetext{
${ }^{79}$ At 7.

${ }^{80}$ Foreign Minister Murray McCully; see Trevett, Claire "McCully 'optimistic but not confident' over Ross Sea deal" The New Zealand Herald (online ed, 22 October 2013).

${ }^{81}$ CCAMLR Commission Report of the Second Special Meeting of the Commission, above n 71, at [3.61].

${ }^{82}$ B.C. O'Leary and others "The first network of marine protected areas (MPAs) in the high seas: The process, the challenges and where next", above n 65, at 603.

${ }^{83}$ OSPAR Commission "The North East Atlantic" < www.ospar.org>.

${ }^{84}$ CCAMLR Article II.
} 
economic benefits from keeping fishing grounds open against the long-term benefits of conservation.

New elements not present at the time that CCAMLR was negotiated may tip the balance between rational use and conservation in favour of use. ${ }^{85}$ The unprecedented opening of the Southern Ocean to global fishing operations, and the fact that most CCAMLR members have an interest in fishing threaten to limit conservation efforts. ${ }^{86}$ Increased technical capability has extended the spatial and temporal range of human activities, and provided more powerful fishing methodologies and processing options. ${ }^{87}$ Any State can become a CCAMLR member, so long as it is engaged in research or harvesting in the CCAMLR area. Since the Convention came into force, the number of non-fishing States has remained relatively stable, whilst the number of fishing States has increased. ${ }^{88}$ In 1982, CCAMLR comprised of a one to two ratio of fishing to non-fishing States. ${ }^{89}$ Over the last ten years, fishing States now outnumber nonfishing States by a five to three ratio. ${ }^{90}$

The economic interest in fisheries is now prevalent in the CCAMLR Commission. This is partly attributable to the rise in the economically lucrative toothfish industries. The Antarctic and Patagonian are the two types of toothfish, with the Patagonian toothfish's worth being analogised to 'white gold'. ${ }^{91}$ States that had previously not fished for toothfish (such as New Zealand and Australia) began to do so. Additionally new States that joined CCAMLR, including China, Namibia and Uruguay, soon began fishing operations, some focused explicitly on toothfish. ${ }^{92}$ CCAMLR has not been able to develop and manage limits to the toothfish fishing capacity, and as a result the Ross Sea fishery has grown more crowded. ${ }^{93}$ The krill fish industry, which initially sparked the negotiation and adoption of CCAMLR, at the turn of the

\footnotetext{
${ }^{85}$ Fabra and Gascon, above $\mathrm{n}$ 52, at 583.

${ }^{86}$ At 583.

${ }^{87}$ Beth C. Clark and Alan D. Hemmings "Problems and Prospects for the Conservation on the Conservation of Antarctic Marine Living Resources Twenty Years On” (2001) 4(1) Journal of International Wildlife Law \& Policy 47 at 49.

${ }^{88}$ Brooks, above n 67, at 295.

${ }^{89}$ At 295.

${ }^{90}$ At 295.

91 "Toothfish fisheries" CCAMLR <www.ccamlr.org $>$.

92 Brooks, above n 67, at 295.

${ }^{93}$ At 296.
} 
century experienced a renewed and substantially increased interest. ${ }^{94}$ These fisheries interests can either result in the inability to reach a consensus required to pass a conservation measure, or the interests can substantially weaken a proposal through a number of ways such as redrawing boundaries to exclude the fishing ground, and reducing the size of a no-take area. The South Orkney MPA, and the other two proposed MPAs have reflected the prevalence of this interest.

\section{$1 \quad$ South Orkney Islands}

The purpose of the South Orkney Islands MPA is to provide a scientific reference area, and to conserve important predator foraging areas. ${ }^{95}$ The MPA was only designated in 2009 after its boundaries were re-drawn to exclude a commercial fishery in the region. ${ }^{96}$ The revised MPA proposal by the United Kingdom was accepted by Japan only after the original proposal was amended to exclude an area where fishing activity had been carried out by Japan. ${ }^{97}$ Japan noted that the amended proposal constituted a good precedent for future deliberations, with the hope that the same consideration is given to fisheries interests going forward. ${ }^{98}$ Further, the proposal went through little resistance from members, with the exception of an area in the northern part which was excised from the proposal to enable a potential exploratory crab fishery. ${ }^{99}$

\section{Ross Sea region}

The Ross Sea region is amongsr the most pristine natural regions in the world, and of tremendous conservation and scientific value as a reference area for research and monitoring of climate and other environmental change, and for a better understanding of ecosystem function. ${ }^{100}$ It contains habitats for a considerable population of mammals and birds, and there

\footnotetext{
94 Clark and Hemmings, above n 87, at 59.

${ }^{95}$ CCAMLR Commission Conservation Measure 91-03 Protection of the South Orkney Islands southern shelf (2009).

${ }^{96}$ Scott "Conservation on the High Seas: Developing the Concept of the High Seas Marine Protected Areas", above $n$ 53, at 855 .

${ }^{97}$ CCAMLR Commission Report of the Twenty-Eight Meeting of the Commission, above n 54, at [7.4].

98 At [7.4]

${ }^{99}$ Brooks, above $\mathrm{n}$ 63, at 282.

${ }^{100}$ A proposal for the establishment of a Ross Sea Region Marine Protected Area, Delegations of New Zealand and the USA, 31 May 2013, CCAMLR-SM-II/04 at [3].
} 
is high level of scientific understanding and information about the Ross Sea region, making it a uniquely desirable candidate for protection. ${ }^{101}$ The Ross Sea proposal was developed by New Zealand and the US initially independently, but the Commission directed both countries to agree on a common proposal. The joint proposal, brought to the Commission during the July 2013 special meeting, divided the MPA into three protection categories; a general protection, special research zone, and spawning zone. ${ }^{102}$

A substantial fishery for Antarctic toothfish occurs in the Ross Sea region, with New Zealand the first country to fish for it in 1997, and has since been followed by many other countries. ${ }^{103}$ The initial boundaries proposed by New Zealand at the 2012 CCAMLR meeting deliberately excluded a small but commercially lucrative toothfish industry, known as the 'wedge'. ${ }^{104}$ Whereas the US proposal included the toothfish fishing grounds within the MPA boundaries. ${ }^{105}$ New Zealand did not want to displace its commercial fishery, and emphasised that the region is essential to maintaining the continuity and integrity of the existing toothfish tagging programme. ${ }^{106}$ The special research zone reflects this compromise, as light fishing and tagging can occur within the zone. ${ }^{107}$

\section{$3 \quad$ East Antarctic}

A similar picture is also painted for the East Antarctic proposal put forward by Australia and France. The proposal brought to the July 2013 special meeting encompassed an area of 1.6 million square kilometers. The seven proposed representative areas within the proposal host important ecological processes, and provide a reference area for understanding the effects of climate change on ecosystems. ${ }^{108}$ Four of the seven MPAs were designed to encompass

101 "Why the Ross Sea region" New Zealand Ministry of Foreign Affairs and Trade <www.mfat.govt.nz/rosssea-mpa>.

102 A proposal for the establishment of a Ross Sea Region Marine Protected Area, above n 100, at [8].

${ }^{103}$ NIWA "Antarctic Toothfish Fishery in the Ross Sea" <www.niwa.co.nz>.

${ }^{104}$ Karen Scott "Marine Protected Areas in the Southern Ocean" in Erik J Molenaar, Alex G Oude Elferink and Donald R. Rothwell (eds) The Law of the Sea and the Polar Regions: Interactions between Global and Regional Regimes (Martinus Nijhoff Publishers, Leiden, 2013) at 133.

105 At 133. The US does not engage in toothfish fishing; see Brooks, above n 67, at 285.

${ }^{106}$ A proposal for the establishment of a Ross Sea Region Marine Protected Area, above n 100, at [10].

${ }^{107}$ CCAMLR Commission Report of the Thirty-First Meeting of the Commission, October-November 2012, CCAMLR-XXXI at [7.72].

108 "A proposal for a representative system of Marine Protected Areas in the East Antarctic planning domain" Australia Department of the Environment, Antarctic Division <www.antarctica.gov.au>. 
foraging areas of top predators as well as suspected nursery grounds for Antarctic krill and toothfish. ${ }^{109}$ The proposal, however, displaces little fishing and excludes most of Prydz Bay, an area that supports the most economically viable toothfish fishery in the region and is also the region's most biologically productive area. ${ }^{110}$

\section{$4 \quad H o w$ can a balance be achieved?}

Fishing is an important economic activity for coastal States. It would be an unattractive and infeasible proposal to completely leave out economic considerations, as well as undermining the aim of rational use. There would be little incentive for States to be cooperate if fisheries activities were always excluded in MPAs. Taken to the other extreme, to exclude fisheries regions completely from a MPA designation will preclude meaningful integrated ecosystem-based management. ${ }^{111}$ The balance must be addressed within the MPA framework for comprehensive coverage. The benefit of various types of protection measures, such as notake to special-research zones, allows for some creativity and innovation to accommodate both interests. The cooperation between New Zealand and the US over the Ross Sea fishery exhibits this. Yet, neither the Ross Sea or East Antarctic proposals have been adopted. Linked to the notion of a sunset clause raised by CCAMLR members, is that once created, the sheer size and potential long duration of the MPAs could limit future exploitation in areas that have not yet been assessed for viable fisheries. ${ }^{112}$ The South Orkney proposal, which excised the northern area for a potential fishery, illustrates this concern as even a potential fishery can influence the design of a MPA. CCAMLR's mandate has the potential to turn into an intractable conflict dividing States who seek protection measures and those that support the fisheries status quo.

\section{Consensus Voting and Membership Composition}

Consensus voting is required under CCAMLR and OSPAR to establish MPAs. ${ }^{113}$ Amongst CCAMLR members this can lead to weaker MPAs from the need to compromise due

\footnotetext{
${ }^{109}$ Brooks, above n 67, at 287.

${ }^{110}$ At 287.

${ }^{111}$ Scott "Conservation on the High Seas: Developing the Concept of the High Seas Marine Protected Areas", above $\mathrm{n} 53$, at 856.

112 Brooks, above n 67, at 290.

${ }^{113}$ CCAMLR, art 12(1) and OSPAR, art 13(1).
} 
to the interests outlined above. A potential option is to persuade Russia to support the Ross Sea protected area measure on the understanding that it can subsequently lodge a formal objection to it. ${ }^{114}$ While an opt-out procedure exists under CCAMLR Article IX 6(c) and (d), the full procedure has never been activated and only one technical objection to a conservation measure has been made since 1982. ${ }^{115}$ Article IX 6(d) can then allow any member of CCAMLR to also declare it is no longer able to accept the conservation measure; potentially allowing a domino effect where multiple States opt-out. Diplomatic pressure can reduce this likelihood, but the question is how many more times will Russia object to the Ross Sea proposal. It could create an unfortunate precedent for CCAMLR, and dampen motivation and political will to continue to try create a network of MPAs.

Membership composition may also account for differing experiences between the two organisations, resulting in variations in levels of cooperation, political will, and common ground. Of the 15 OSPAR contracting parties, 12 are members of the European Union (EU). The remaining being Iceland, Norway and Switzerland, form their own European Free Trade Association. ${ }^{116}$ Further, the members of OSPAR are also represented in NEAFC through the EU. Russia is the only member of NEAFC that is not party to OSPAR.

In contrast, the 24 CCAMLR parties reflect diverse interests, with members ranging from India, China, the EU, Namibia, Russia, and the US. These States have different levels of economic development, political systems, and level of input from civil society. For example, New Zealand and Australian governments face pressure from non-governmental organisations such as Greenpeace and the World Wildlife Fund to establish MPAs. CCAMLR members do not have to be party to the Antarctic Treaty, but Articles III to $\mathrm{V}$ of the Convention requires them to observe the principles and purpose, as well as some specific obligations of the Treaty. 50 States have signed the Antarctic Treaty, and there are 29 Consultative Parties who have voting rights. The mix of CCAMLR members and ATCP are largely similar. There are six

\footnotetext{
${ }^{114}$ University of Canterbury "Ross Sea protected area proposal fail but not all lost” (press release, 17 July 2013) accessed at $<$ www.scoop.co.nz $>$.

${ }^{115}$ Evelyne Meltzer The Quest for Sustainable International Fisheries: regional efforts to implement the 1995 United Nations Fish Stock Agreement (National Research Council of Canada, Ottawa, 2009) at 193.

116 The European Free Trade Association "The EFTA States" < www.efta.int $>$.
} 
States that are ATCPs but are not members of CCAMLR. ${ }^{117}$ Whilst the EU and Namibia are CCAMLR members, but not ATCPs. ${ }^{118}$

OSPAR has made relatively swift progress in MPA designation as the contracting parties already have well-established cooperative relationships on issues of environmental protection. ${ }^{119}$ The EU Common Fisheries policy also makes cooperation easier in NEAFC. These countries have a history of cooperation and similar economic, social, and political interests with some prioritisation of environmental protection. Consensus voting is easier where there is better established cooperation and regional integration. The MPAs lying on the Portuguese extended continental shelf represents an example of the benefits of established regional cooperation.

\section{E Overlapping Extended Continental Shelf Claims}

A challenge for OSPAR has been with coastal States who seek to extend the outer limits of their continental shelf into proposed MPAs. Portugal has supported OSPAR and has been pursuing protection with the Commission, whereas Iceland has taken a different approach. A coastal State's rights over the continental shelf are inherent and do not require a specific legal proclamation. ${ }^{120}$ States can, however, submit their claim to the United Nations (UN) Commission on the Limits of the Continental Shelf for a final and binding recommendation over the establishment of the continental shelf's outer limits. ${ }^{121}$ The coastal State has the right to claim its competence to exercise its duty to protect the marine environment and have it respected in all of the maritime areas under its jurisdiction. ${ }^{122}$ The coastal State's jurisdiction over activities on the seabed/subsoil can potentially undercut attempts made by OSPAR to regulate activities in the water column, unless the coastal State recognises the importance of environmental protection and seeks to cooperate with OSPAR.

\footnotetext{
${ }^{117}$ Bulgaria, Czech Republic, Ecuador, Finland, the Netherlands, and Peru are ATCPs but not CCAMLR members.

${ }^{118}$ Note that the Netherlands, Bulgaria, Finland and the Czech Republic are EU member countries, potentially allowing their concerns to be voiced in CCAMLR.

${ }^{119}$ B.C. O'Leary and others "The first network of marine protected areas (MPAs) in the high seas: The process, the challenges and where next", above n 65, at 603 .

${ }^{120}$ M.C. Ribeiro "The 'Rainbow': The First National Marine Protected Are Proposed Under the High Seas" (2010) 25 IJMCL 183 at 190.

${ }^{121}$ UNCLOS, art 76(8).

${ }^{122}$ Ribeiro, above n 120, at 192.
} 
The Charlie-Gibbs South and the Milne Seamount Complex are the only MPAs in ABNJ where the seabed, subsoil and water column are protected collectively by OSPAR. When the $\mathrm{ABNJ}$ sites were proposed it was assumed that there was no national jurisdiction over the seabed and subsoil as it was located in the Area. At the same time, Portugal's domestic Task Group for the Extension of the Portuguese Continental Shelf indicated that four of the proposed OSPAR MPAs overlapped with the outer limits of the Portuguese continental shelf. ${ }^{123}$ These were the Altair Seamount, Antialtair Seamount, Josephine Seamount, and Mid-Atlantic Ridge North of the Azores. Portugal therefore exercises prescriptive and enforcement jurisdiction over the seabed and subsoil in these MPAs.

Fortunately, Portugal recognised its obligations under Article 192 and assumed responsibility prior to the final conclusion of the UN Commission's recommendation. Relevant conservation measures in these MPAs are to be coordinated between the OSPAR Commission and Portugal; with Portugal establishing necessary measures in the seabed, and OSPAR doing so for the superjacent water column. ${ }^{124}$ Without the support of Portugal for these MPAs, the current OSPAR network of high seas MPAs is unlikely to have been established. ${ }^{125}$ The willingness to cooperate prevents legal conflicts, such as unregulated boundary issues, that may be intractable and without such willingness the legal complexities cannot be used to deter engagement by other member States. ${ }^{126}$

Iceland's extended continental shelf claim has proved more difficult for OSPAR, as Iceland is not yet willing to enter into co-management discussions. ${ }^{127}$ In 2009 , Iceland claimed an extended continental shelf which overlapped with the proposed Charlie-Gibbs MPA adopted 'in principle' in 2008. This resulted in the Charlie-Gibbs South MPA (designated in 2010) protecting the seabed, subsoil and water column lying outside the Icelandic submission. In 2012, the Charlie-Gibbs North MPA was added, with the result that OSPAR would solely protect the water column superjacent to the seabed of the site, without additional protective

\footnotetext{
${ }^{123}$ At 190.

124 Tanaka "Reflections on High Seas Marine Protected Areas: A Comparative Analysis of the Mediterranean and the North-East Atlantic Models", above n 44, at 322 and 323.

${ }^{125}$ B.C. O'Leary and others "The first network of marine protected areas (MPAs) in the high seas: The process, the challenges and where next", above n 65, at 602 .

${ }^{126}$ At 604.

${ }^{127}$ At 602.
} 
measures by Iceland for the seabed. ${ }^{128}$ Management measures are to be developed and adopted with respect to the water column only in the Charlie-Gibbs North. ${ }^{129}$ At the 2010 Ministerial Meeting, the parties agreed to apply due diligence when exercising any possible sovereign rights, and to engage actively with each other when conducting activities to ensure they take the same approach. ${ }^{130}$

\section{F Why has OSPAR been more successful than CCAMLR?}

OSPAR has more successfully designated a representative network of MPAs than CCAMLR due to the absence of competing fisheries interests, better cooperation amongst likeminded States attributable to regional integration, and compromise over the overlapping extended continental shelf claims. The dual legal regimes of the seabed/subsoil and water column appear legally difficult to co-manage; however, its success lies in the willingness of States to engage cooperatively with OSPAR. ${ }^{131}$ It is noteworthy that CCAMLR parties were able to reach a consensus over the South Orkney Islands and agree to afford the MPA the highest protective measures, however, even diluted proposals for the Ross Sea and East Antarctic cannot be agreed on. This reflects the tension between member States on the interpretation of CCAMLR objectives. Balancing rational use and conservation objectives where fishing interests are prevalent will continue to prove to be a difficult task for CCAMLR. Issues over the requisite scientific certainty and the inclusion of a sunset clause have distracted from the big picture aims of a MPA and the application of the precautionary approach. The Ross Sea and East Antarctic proposals cover a considerable size of the Antarctic (over roughly 1 million square kilometers each), compared to the 94, 000 square kilometer South Orkney MPA, also adding to the difficulty in reaching a consensus. One of the contributing factors to OSPAR's success in designating a network may also have been the momentum to create the six MPAs in ABNJ simultaneously. The difficulty for OSPAR, however, will now lie in comanaging the MPAs.

\footnotetext{
${ }^{128}$ Julien Rochette and others "The regional approach to the conservation and sustainable use of marine biodiversity in areas beyond national jurisdiction" (2014) 49 Marine Policy 109 at 111.

${ }^{129}$ Charlotte Salpin and Valentina Germani "Marine Protected Areas Beyond Areas of National Jurisdiction: What's Mine is Mine and What You Think is Yours is also Mine” (2010) 19(2) RECIEL 174 at 182. ${ }^{130}$ At 182.

${ }^{131}$ B.C. O'Leary and others "The first network of marine protected areas (MPAs) in the high seas: The process, the challenges and where next", above n 65, at 602.
} 


\section{Challenges Facing Both Regions in Managing MPAs}

Designating MPAs is just the start of the process. Ensuring the MPAs are managed to carry out their conservation objectives requires the political will for compliance and enforcement by member States and organisations. The following section will discuss differences in both regions for managing the MPAs. Incorporating an integrated approach will be seen as more difficult in the North-East Atlantic; as OSPAR's competence is limited and requires working with different organisations. Whereas, the ATS offers a model management framework, with coordination between CCAMLR and the Environment Protocol bodies potentially strengthening the protection of the Antarctic marine environment. Importantly, both regions must avoid a duplication of efforts, and ensure a high level of coordination between the relevant organisations to avoid undermining each other's conservation measures.

Each OSPAR MPA is required to have a management plan, and there are a range of soft measures to enhance management such as awareness raising, information building, and science sharing. ${ }^{132}$ For MPAs within national jurisdiction, States are required to annually report on actions or measures taken to implement the management plan. OSPAR has no reference to implementation or enforcement of conservation objectives in the decisions and recommendations establishing the MPAs in ABNJ. ${ }^{133}$ Further, the OSPAR Commission is not managing any control and enforcement activities in the MPAs (see the next part for further discussion on compliance and enforcement). ${ }^{134}$ OSPAR relies on cooperation with other organisations, and making use of the control activities that its member States undertake. ${ }^{135}$ If the OSPAR Commission considers that action is desirable under the competency of another organisation, it can draw the issue to the attention of that body. ${ }^{136}$

\footnotetext{
${ }^{132}$ See for example OSPAR Commission OSPAR Recommendation 2010/12 on the Management of the Milne Seamount Complex Marine Protected Area (2010) at [3.3].

${ }^{133}$ Nele Matz-Luck and Johannes Fuchs "The impact of OSPAR on protected area management beyond national jurisdiction: Effective regional cooperation or a network of paper parks?” (2014) 49 Marine Policy 155 at 161.

${ }^{134}$ Ingrid Kvalvik "Managing institutional overlap in the protection of marine ecosystems on the high seas. The case of the North East Atlantic” (2012) 56 Ocean \& Coastal Management 35 at 41.

135 At 41.

${ }^{136}$ OSPAR Annex V, art 4.
} 
The Conservation Measure establishing the South Orkney Islands MPA in 2009 states that it will be reviewed at the CCAMLR Commission's regular meeting in 2014, based on advice from the SC-CAMLR, and at subsequent five-year periods. ${ }^{137}$ Conservation Measure 91-04, on the general framework for establishing a MPA, indicates a management plan to achieve the objectives of the MPA should be established, and that once developed and adopted by the Commission it will be annexed to the conservation measure. ${ }^{138}$ No such management plan exists for the South Orkney Islands MPA as Conservation Measure 91-04 was adopted after the creation of the MPA. ${ }^{139}$ SC-CAMLR has discussed this problem, and recognises that better understanding is needed to manage the MPA. ${ }^{140}$ It remains to be seen how the 2014 review of the South Orkney MPA will be conducted, what recommendations come out of process, and whether these will be implemented by the Commission. The absence of a management plan will make it difficult to evaluate the MPA's effectiveness as there is no benchmark to assess how protective measures have been carried out.

Given the lack of information concerning the management of the MPAs to date, the following discussion will draw on the potential for an integrated management approach in the areas and what the issues to date have been.

\section{A Institutional Overlap: NEAFC's Role}

Global and regional institutions exist with a mandate to regulate the activities in the North-East Atlantic ABNJ. All these institutions (OSPAR, NEAFC, ISA and IMO) are functionally linked by a de facto interaction. ${ }^{141}$ They have overlapping competencies regarding issues relevant to the protection and conservation of marine biodiversity and ecosystems. ${ }^{142}$ For example, the IMO can develop measures for Particularly Sensitive Sea Areas, and NEAFC has the ability to close areas to fishing. The region provides a unique opportunity to develop

${ }^{137}$ CCAMLR Commission Conservation Measure 91-03 Protection of the South Orkney Islands southern shelf (2009) at [9].

${ }^{138}$ CCAMLR Commission Conservation Measure 91-04 General framework for the establishment of CCAMLR Marine Protected Areas (2011) at [4].

${ }^{139}$ Scientific Committee for the Conservation of Antarctic Marine Living Resources Report of the Thirtieth Meeting of the Scientific Committee, October 2011, SC-CAMLR-XXX at [5.25].

${ }^{140}$ Scientific Committee for the Conservation of Antarctic Marine Living Resources Report of the Thirty-Second Meeting of the Scientific Committee, October 2013, SC-CAMLR-XXXII at [5.20].

${ }^{141}$ Kvalvik, above n 134, at 36.

142 At 36. 
integrated management given this institutional overlap. If not properly managed, however, this overlap can result in impractical or illogical conservation measures if one institution adopts measures that do not, or only partially correspond with that of another. ${ }^{143}$ Kvalvik's thesis is that this overlap can either give rise to conflictual or synergic effects. Institutions belonging to different policy fields (fishing, shipping and environmental protection) will frequently have considerable diverging objectives. ${ }^{144}$ If the overlap can result in a step toward harmonised measures, or at least coordination of activities, it could be expected that organisations would take steps to address and develop procedures to manage the overlap. ${ }^{145}$ Three features characterise the overlap.

\section{$1 \quad$ Geography}

As NEAFC is the major RFMO in the region, OSPAR is largely reliant on it to comanage the MPAs. There is a complete geographic overlap between NEAFC and OSPAR's regulatory areas, with the exception of areas under Russian jurisdiction in the Barents Sea which are not covered by OSPAR. ${ }^{146}$

\section{Jurisdiction}

OSPAR's jurisdiction to regulate harmful activities to the marine environment does not extend to fishing and shipping activities. It has a general mandate to regulate marine scientific research and deep-sea tourism activities. ${ }^{147}$ When it is considered that the MPAs cover the MidAtlantic Ridge, hydrothermal vents, and seamounts; the ability to regulate scientific research is important as it poses a major threat to the MPAs. Further, the OSPAR Commission has identified it can regulate activities including oil and gas exploitation, construction of artificial islands, reefs, installations and structures, and placement of cables and pipelines. ${ }^{148}$ Kvalvik

\footnotetext{
143 At 36.

144 At 36.

145 At 36.

146 At 37.

${ }^{147}$ Julien Rochette and others "The regional approach to the conservation and sustainable use of marine biodiversity in areas beyond national jurisdiction", above $\mathrm{n} 128$, at 113.

${ }^{148}$ Harm Dotinga and Erik J, Molenaar The Mid-Atlantic Ridge: A Case Study on the Conservation and Sustainable Use of Marine Biodiversity in Areas beyond National Jurisdiction (IUCN, Switzerland, 2008) at
} 13. 
characterises this as an overlap in the objective, to conserve marine ecosystems on the high seas, but not in the activities that can be regulated. ${ }^{149}$ Both OSPAR and NEAFC have the competence to adopt spatial management measures on the high seas; NEAFC by closing areas certain areas for fisheries and OSPAR by establishing MPAs. ${ }^{150}$

\section{$3 \quad$ Membership}

A certain overlap in core State membership is a necessary condition for enhancing management of the institutional overlap. ${ }^{151}$ The OSPAR regime relies on the fact that contracting parties are also represented in respective RFMOs, and would implement OSPAR measures in the respective RFMO organs. ${ }^{152}$ With the exception of Russia, all parties to NEAFC are also parties to the OSPAR Convention. However, since the EU fisheries are managed under the Common Fisheries Policy, the member States are represented by one delegation in NEAFC. ${ }^{153}$

\section{(a) Agency Participation}

Agency participation is an area where there is no distinct overlap. The delegates to NEAFC come from different fisheries agencies, whilst the delegates to the OSPAR meetings come mainly from the environmental agencies. ${ }^{154}$ Iceland and Norway are the only parties where the ministries of fisheries have participated at OSPAR meetings. ${ }^{155}$ Coordination of national agencies is important for management of the institutional overlap to ensure consistent practices from each State and awareness of developments in each organisation. Significantly, both institutions receive scientific advice from the International Council for the Exploration of the Sea (ICES) to which all the member States are parties. ${ }^{156}$

\footnotetext{
${ }^{149}$ Kvalvik, above n 134, at 37 and 38.

150 Julien Rochette and others "The regional approach to the conservation and sustainable use of marine biodiversity in areas beyond national jurisdiction”, above n 128, at 113 .

${ }^{151}$ Kvalvik, above n 134, at 36.

${ }^{152}$ Luck and Fuchs, above n 133, at 164.

${ }^{153}$ Kvalvik, above n 134, at 37.

${ }^{154}$ At 37.

155 At 37.

${ }^{156}$ At 37.
} 
Once the overlapping areas are identified, managing the overlap is the focus. There is no modus operandi in OSPAR for interacting with other organisations. The Commission is free to adopt the most appropriate and effective mode of interaction in accordance with OSPAR's general objectives. ${ }^{157}$ The mode might be different depending on the organisation, and range from awareness-raising, encouraging mutual observer status, to using instruments such as a memorandum of understanding to bring to life concrete proposals for action. ${ }^{158}$ One example of modest management of the overlap is the partial alignment of NEAFC closure areas with OSPAR MPAs.

\section{The problem with NEAFC closure areas}

In 2006 and 2009, responding to international concerns over destructive fishing practices, the UN General Assembly adopted two resolutions which called upon States and RFMOs to take specific measures to protect vulnerable marine ecosystems from the adverse impacts of bottom fisheries in the high seas, and to ensure the long-term sustainability of deepsea fish stocks. ${ }^{159}$ In reaction to this in 2009 , NEAFC closed five areas to bottom trawling in ABNJ. These closure areas prohibit the use of fishing gear likely to contact the seafloor during the normal course of a fishing operation. ${ }^{160}$ These measures will remain in place until 2015, at which point the situation will be reevaluated. ${ }^{161}$ Some of these closure areas overlap with OSPAR's MPAs, as seen in the figure below. Although the OSPAR Commission established the MPAs in September 2010, the MPAs were adopted in principle in 2008, and a member of NEAFC was a member of the OSPAR MPA group. NEAFC was aware of OSPAR developments and vice versa, and OSPAR tried to form some geographical alignment of both

\footnotetext{
${ }^{157}$ Petra Drankier "Marine Protected Areas in Areas beyond National Jurisdiction" (2012) 27 IJMCL 291 at 317. 158 At 317.

${ }^{159}$ Elisabeth Druel and others Governance of marine biodiversity in areas beyond national jurisdiction at the regional level: filling the gaps and strengthening the framework action (Institute for Sustainable Development and International Relations, 2012) at 19.

160 Tanaka "Reflections on High Seas Marine Protected Areas: A Comparative Analysis of the Mediterranean and the North-East Atlantic Models", above n 44, at 319.

${ }^{161}$ Druel and others, above n 159, at 19.
} 
areas. The Milne Seamount Complex and Josephine Seamount are devoid of bottom fishing protection and some MPAs are only partially covered by the NEAFC closures.

Figure 4 OSPAR MPAs and NEAFC Closure Area ${ }^{162}$

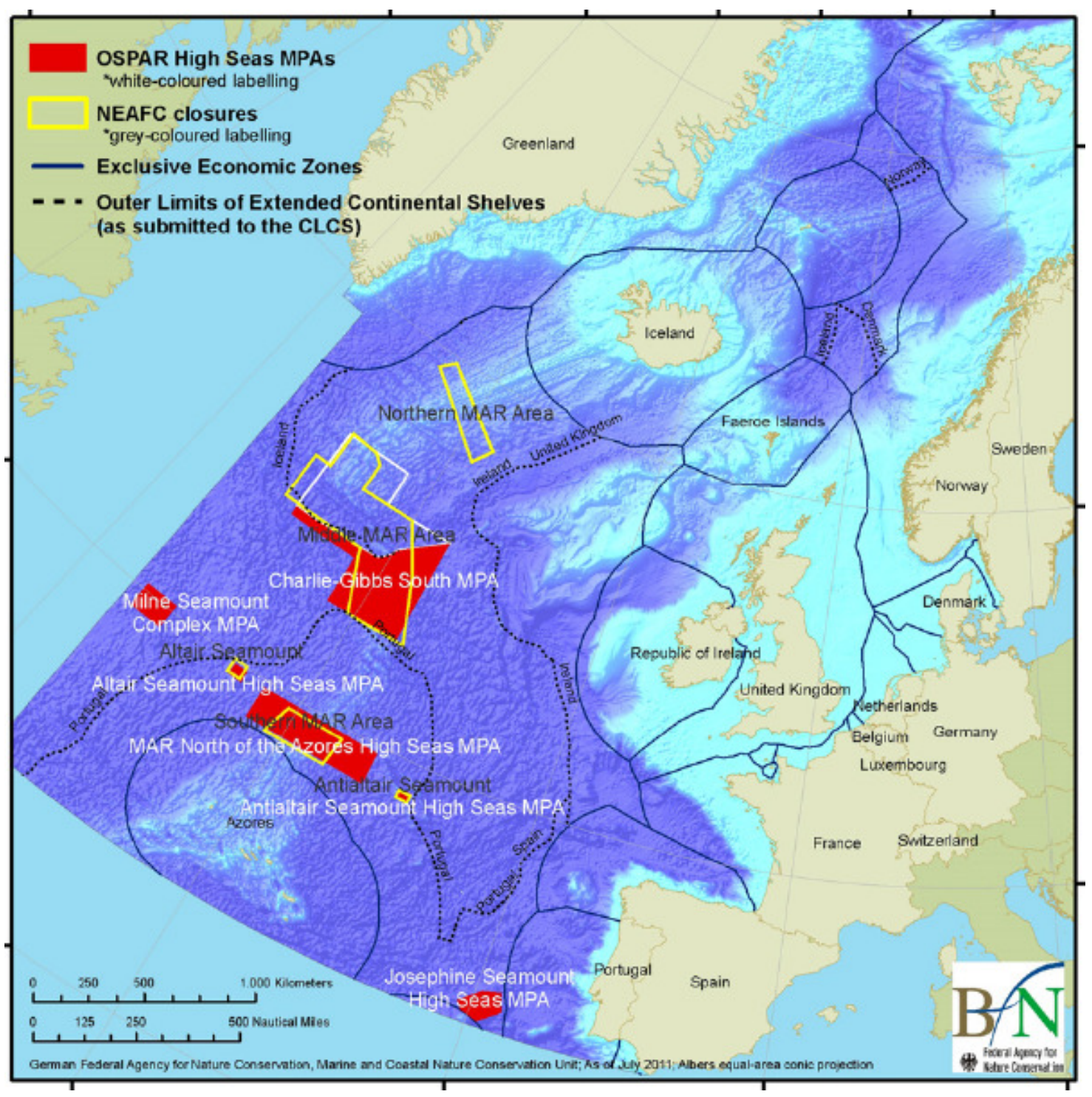

The mixed alignment of NEAFC closure areas with OSPAR MPAs is illustrative of the problems of coordination facing the region. The result is that some areas are closed for bottom fishing but not closed for other activities, and similarly MPAs are established by the OSPAR

${ }^{162}$ OSPAR Commission 2012 Status Report on the OSPAR Network of Marine Protected Areas, above n 42, at 30 . 
Commission where bottom fishing is allowed. ${ }^{163}$ Further, NEAFC has classified 'existing bottom fishing areas' where bottom fishing has taken place and 'new bottom fishing areas' where bottom fishing has not taken place. ${ }^{164}$ One of NEAFC's existing fishing areas overlaps with the Josephine Seamount High Seas MPA, and may undermine the measures adopted by OSPAR. The ICES, giving advice after a special request from NEAFC in June 2013, recommended that NEAFC should close bottom fisheries along the boundary corresponding with the Josephine Seamount MPA. ${ }^{165}$ The ICES supported OSPAR's designation of the MPA on the basis that the area included vulnerable marine ecosystem species, and the ICES presented further historical evidence supporting this position. ${ }^{166}$ The ICES stated that the present status of the areas as an 'existing fishing area' by NEAFC creates a risk of significant adverse impacts to the area from bottom fishing gear. ${ }^{167}$ It seems surprising that this particular area's protection measures are not aligned given that both organisations receive the same scientific data. Yet, it reflects the different dynamics and politics each organisation faces, as well as the difficulty from no universally accepted criteria for determining a protected area. NEAFC has not yet added the Josephine Seamount as a closed area, as the EU maintains the seafloor is subject to the national jurisdiction of Portugal. ${ }^{168}$ This seems contradictory to Portugal's intent to protect the site, as well as the alignment of closure areas already within Portugal's extended continental shelf claim. NEAFC has agreed it will continue to work with OSPAR on this issue. ${ }^{169}$

Kvalvik notes that the purpose of establishing a MPA may not be solely to protect the area from bottom fishing. ${ }^{170}$ For example, fishing is not taking place in areas deeper than 2000 meters, so the areas closed for bottom fishing by NEAFC may not extend as far out from seamounts as the OSPAR MPAs. ${ }^{171}$ However, the areas should be harmonised at least to such a degree that it does not create a situation where regulation undertaken by one institution

\footnotetext{
${ }^{163}$ Kvalvik, above n 134, at 38.

164 Drankier, above n 157 , at 326.

165 Vulnerable deep-water habitats in the NEAFC Regulatory Area (ICES Advice, Special Request, June 2013) at 9 .

166 At 9 .

167 At 9.

${ }^{168}$ NEAFC Report of the $32^{\text {nd }}$ Annual Meeting of the North-East Atlantic Fisheries Commission (11-15

November 2013) at 9.

169 At 9.

${ }^{170}$ Kvalvik, above n 134, at 40.

${ }^{171}$ At 40.
} 
violates protective measures adopted by the others. ${ }^{172}$ Aligning the measures can also aid the application of the precautionary approach to regulate the catch of deep-sea fisheries and provide protection where vulnerable marine ecosystems are known or likely to exist. ${ }^{173}$

Even though a Memorandum of Understanding was signed in 2008 between OSPAR and NEAFC, little effective action was taken by both to align closure areas and proposed MPAs, despite both organisations iterating it. ${ }^{174}$ Interestingly, a proposal to expand the closure areas in line with the draft proposal by OSPAR was put twice at NEAFC, but did not receive sufficient support, and NEAFC closed the areas more or less as proposed. ${ }^{175}$ One reason put forward by the Norwegian representative at NEAFC was that there was not enough time to coordinate with OSPAR. ${ }^{176}$

(b) Where to for OSPAR?

The background to OSPAR's relationship with NEAFC is not perfect, as NEAFC has sometimes viewed OSPAR as encroaching on its jurisdiction. The first meeting between the two institutions was held in 2005, and the relationship has slowly evolved. ${ }^{177}$ Early establishment of cooperation is important to ensure that issues do not arise later down the track. The Memorandum of Understanding clearly reflects their positions, stating that "NEAFC and the OSPAR Commission have complementary competences and responsibilities for fisheries management and environmental protection, respectively, within the North-East Atlantic region" (emphasis added). ${ }^{178}$ The Memorandum includes largely soft measures to allow the free flow of mutually useful information and data, the organisations working together to develop a common understanding of the application of the precautionary approach, encouraging the funding and conduct of marine science to enhance knowledge on conservation,

172 At 40 .

${ }^{173}$ NEAFC Report of the $30^{\text {th }}$ Annual Meeting of the North-East Atlantic Fisheries Commission (Volume I, 7-11 November 2011) at Annex F.

${ }^{174}$ Kvalvik, above n 134, at 39.

175 At 39 and 40.

${ }^{176}$ NEAFC Report of the $28^{\text {th }}$ Annual Meeting of the North-East Atlantic Fisheries Commission (9-13 November 2009) at 14.

${ }^{177}$ Kvalvik, above n 134, at 39.

${ }^{178}$ OSPAR Commission Memorandum of Understanding between the North East Atlantic Fisheries Commission (NEAFC) and the OSPAR Commission (2008). 
and providing reports of each other's meetings. ${ }^{179}$ The more substantive measures include establishing reciprocal observer arrangements, and drawing to the attention of each other concerns raised during the course of work for the protection of the marine ecosystem. ${ }^{180}$ The reciprocal observer arrangement can be especially useful for OSPAR parties to observe implementation of proposed management measures. Further, allowing the OSPAR Commission observer status on the Permanent Committee on Control and Enforcement of NEAFC who deal with questions relating to monitoring, control and surveillance of the NEAFC regulatory area would enhance those management efforts. ${ }^{181}$

Both organisations are now working to ensure better coordination. OSPAR has also signed cooperative agreements with the ISA and the IMO. The process of designating MPAs has led to greater cooperation and discussion with all key competent authorities, and it is hoped this will flow on to management. For example, the Charlie-Gibbs South MPA discussions during 2010 included a meeting between NEAFC, the IMO, ISA and OSPAR devoted to the discussion of co-management. ${ }^{182}$ Shared scientific information from ICES is also a significant factor pointing towards greater coordination and policy alignment, and OSPAR and NEAFC have submitted a few joint proposals to the ICES for consideration. OSPAR can provide a valuable platform to facilitate cooperation and communication amongst contracting parties, and other organisations for the establishment and management of MPA networks. Cooperation and coordination at the technical level, rather than just attending one another's annual Commission meetings, is also key to exploiting the institutional overlap and avoiding duplication of work. ${ }^{183}$ If cooperation and coordination is enhanced, the hope is that this will allow more effective and efficient management of the MPAs.

\section{B Potential for an Integrated Approach in the Southern Ocean}

The ATS bodies are in a unique position to create and manage MPAs, although this potential is yet to be fully realised. Fabra and Gascon pose the question of whether this

\footnotetext{
${ }^{179}$ At $[1]$.

${ }^{180}$ At [1].

${ }^{181}$ Kvalvik, above $\mathrm{n} 134$, at 41.

${ }^{182}$ B.C. O'Leary and others "The first network of marine protected areas (MPAs) in the high seas: The process, the challenges and where next", above n 65, at 604.

${ }^{183}$ Kvalvik, above n 134, at 41.
} 
relationship would result in the strengthening of the implementation of an ecosystem approach in Antarctica, or whether it would lead to a dilution of efforts or lost opportunities. ${ }^{184}$ If the political will of the member States exists, CCAMLR and CEP protection measures can be maximised.

\section{$1 \quad$ Overlap between CCAMLR and the Environment Protocol}

There is an obligation of cooperation between the CCAMLR Commission and the ATCM, embodied in Resolution 1 ATCM XXIX (2006). There is a geographic overlap between the Environment Protocol's area of application and CCAMLR, seen in the figure below. The Antarctic Treaty and the Protocol apply to the area south of $60^{\circ}$ south latitude, whilst CCAMLR more widely applies to the entire south of the Antarctic convergence. All of the Antarctic Treaty area and the vast majority of the CCAMLR area fall on the high seas. ${ }^{185}$

Figure 5 CCAMLR and Antarctic Treaty Area ${ }^{186}$

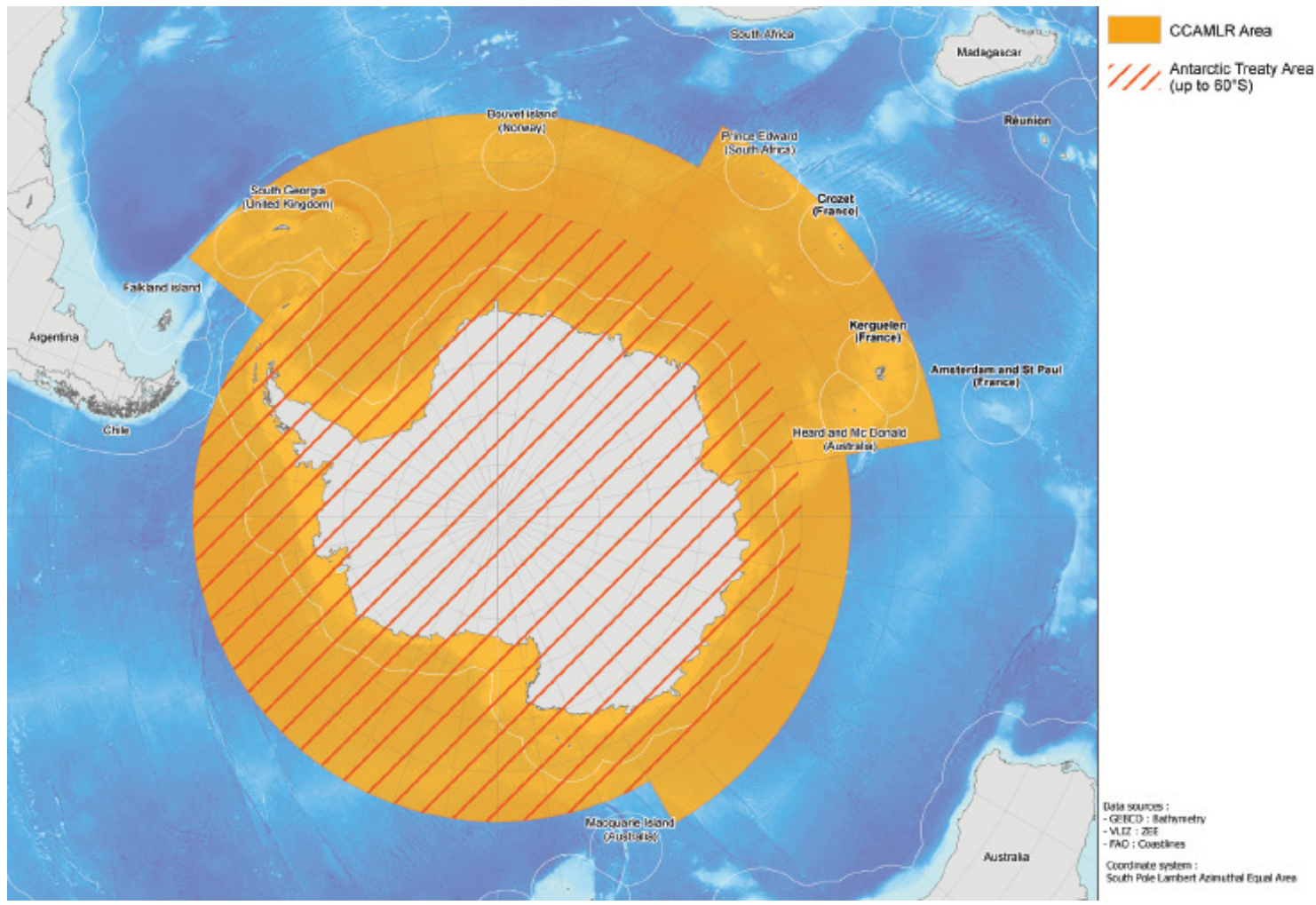

\footnotetext{
${ }^{184}$ Fabra and Gascon, above n 51, at 586.

185 IUCN High Seas Marine Protected Areas (Parks Volume 15(3), IUCN, 2005) at 42.

${ }^{186}$ Druel and others, above n 159, at 36.
} 
A clear jurisdictional overlap of both CCAMLR and the Environment Protocol exists. Article 2 of the Protocol commits contracting parties "to the comprehensive protection of the Antarctic environment and dependent and associated ecosystems". ${ }^{187}$ Further, the protection of the Antarctic environment shall be a fundamental consideration in the planning and conduct of all activities in the Antarctic Treaty Area. ${ }^{188}$ The Protocol does not exclude the protection of marine living resources from its area of competence, but in practice, marine living resources are left to CCAMLR to oversee. ${ }^{189}$ The difference in jurisdiction is that the Protocol also provides the tools for bringing into consideration a number of activities, such as maritime transportation, bioprospecting, tourism and deep-sea fishing, which can have an impact on the marine ecosystem but are beyond the scope of CCAMLR. ${ }^{190}$ Further, under the ATS framework, both CCAMLR and the ATCPs (through the Environment Protocol) can designate MPAs.

Under Annex V of the Environment Protocol, adopted in 1991 and entered into force in 2002, the ATCP can create both Antarctic Specially Protected Areas (ASPA) and Antarctic Specially Managed Areas (ASMA) to protect environmental, scientific, historic, aesthetic, or wilderness values. ${ }^{191}$ Both of these may encompass marine areas. ASPAs and ASMAs are consistent with the function of a MPA. ${ }^{192}$ Each designated site has a different level of protection afforded to it. ASPAs strictly manage (or even prohibit) activities taking place in order to provide for a higher level of protection of the area. ${ }^{193}$ Mostly small areas of scientific interest have been protected, such as the 30 square kilometer marine ASPA No. 161 at Terra Nova Bay in the Ross Sea designated in 2003 to protect an area of long-term scientific research with high species and habitat diversity. ${ }^{194}$ A permit is required for entry and for all scientific activities taking place in the ASPA, and there are also restrictions on shipping activities within the

\footnotetext{
${ }^{187}$ Environment Protocol, art 2.

${ }^{188}$ Environment Protocol, art 3.

${ }^{189}$ Fabra and Gascon, above n 51, at 585.

${ }^{190}$ At 585.

${ }^{191}$ Environment Protocol Annex V, arts 3 and 4.

192 Scott "Marine Protected Areas in the Southern Ocean", above n 104, at 128.

193 At 128.

${ }^{194}$ IUCN High Seas Marine Protected Areas, above n 185, at 43.
} 
area. ${ }^{195}$ ASMAs can aim to assist in the planning and coordination of activities, avoiding possible conflicts to improve cooperation between parties, or minimise environmental impacts in areas where activities are being conducted or may be conducted in the future. ${ }^{196}$ ASMAs have a non-mandatory code of conduct for multiple uses such as tourism, scientific research, shipping and research station logistics. ${ }^{197}$

The majority of protected marine areas are small coastal zones encompassed in a wider terrestrial protected area. ${ }^{198}$ This has begun to change in past years, and protected zones located entirely in marine areas now exist, although of a modest size. ${ }^{199}$ There are over 70 of these protected areas with the great majority being ASPAs. As at 2012, 10 ASPAs are marine or partly marine, and three of the six ASMAs are partly marine. ${ }^{200}$ They have not, however, been designated as representative examples of major ecosystems. ${ }^{201}$ In 2009 , the CEP agreed to "develop a strategy and work towards the establishment of effective, representative and coherent spatial protection of marine biodiversity" through the use of ASMAs and ASPAs. ${ }^{202}$ The sharing of scientific information and data between the CEP and SC-CAMLR will help this process.

The ATCM must adopt a measure to designate an ASPA or ASMA, and adopt a management plan for that area. ${ }^{203}$ These management plans must be reviewed every five years. ${ }^{204}$ Submission of a proposed management plan for an ASPA or ASMA can be made to the ATCM by any contracting party, the CEP, the Scientific Committee on Antarctic Research, or CCAMLR. ${ }^{205}$ CCAMLR can therefore seek to create an ASPA or ASMA through adopting

\footnotetext{
195 At 43.

196 “Area Protection and Management/Monuments" Secretariat of the Antarctic Treaty <www.ats.aq>.

${ }^{197}$ IUCN High Seas Marine Protected Areas, above n 185, at 43.

${ }^{198}$ Druel and others, above n 159, at 34.

199 At 34.

${ }^{200}$ As per CCAMLR Commission Conservation Measure 91-02 Protection of the values of Antarctic Specially Managed and Protected Areas (2012).

${ }^{201}$ IUCN High Seas Marine Protected Areas, above n 185, at 43.

${ }^{202}$ Cited in Druel and others, above n 159, at 34. See ATCM Final Report of the Thirty-Second Antarctic Treaty Consultative Meeting (Baltimore, April 2009) at [97].

${ }^{203}$ Kees Bastmeijer and Steven van Hengel "The role of the protected area concept in protecting the world's largest natural reserve: Antarctica” (2009) 5(1) Utrecht Law Review 61 at 73.

${ }^{204}$ Rodolfo Andres Sanchez and Evan McIvor "The Antarctic Committee for Environmental Protection: past, present and future" (2007) 43 Polar Record 239 at 242.

${ }^{205}$ Environment Protocol, Annex V, art 5(1).
} 
a management plan agreed to by the ATCP. This will be particularly useful where CCAMLR sees a management gap for a proposed MPA. Importantly also, an ASMA or ASPA requires CCAMLR's approval if it includes a marine component which may impact on harvesting or other CCAMLR activities. ${ }^{206}$ This deliberately provides a mechanism to bring together the Antarctic institutions responsible for the management of all marine-based activities during the process of designation. ${ }^{207}$

\section{$3 \quad$ Management of the overlap}

Molenaar writes that the relatively strong-institutional linkages in the ATS is particularly conducive to integrated ecosystem management. ${ }^{208}$ The CCAMLR Commission and the CEP have committed to the establishment of a representative network of MPAs as a priority, with the CCAMLR Commission recognised as the lead body within the ATS to progress the development of this. ${ }^{209}$ It is important that this clarification between the roles has been identified, with CCAMLR taking the lead for MPAs. This will hopefully result in better coordination and avoid duplication of efforts, provided that the parties agree to conservation measures in the first place.

Both CCAMLR and the ATCP have also identified the respective roles of ASPAs, ASMAs and MPAs. Conservation Measure 91-02 by CCAMLR notes that "a harmonised approach in the ATS to spatial protection may result in having ASPAs and ASMAs designated by the ATCM within CCAMLR MPAs". ${ }^{210}$ ASPAs and ASMAs can therefore serve two different purposes when needed; firstly by granting additional protection to some areas within certain CCAMLR MPAs, and secondly by complementing the network of MPAs being designated in certain areas where there is no MPA but where they can address specific threats that fall outside the mandate of CCAMLR but within the mandate of the ATCM. ${ }^{211}$ Further, Conservation Measure 91-04 states that when a CCAMLR MPA is designated, the Commission

\footnotetext{
206 Environment Protocol, Annex V, art 6(2).

${ }^{207}$ Scott "Marine Protected Areas in the Southern Ocean", above n 104, at 129.

${ }^{208}$ Erik J Molenaar "Managing Biodiversity in Areas Beyond National Jurisdiction” (2007) 22(1) IJMCL 89 at 95.

${ }^{209}$ Report of the Joint CEP/SC-CAMLR Workshop (CEP 11, April 2009) at [7.7].

${ }^{210}$ CCAMLR Commission Conservation Measure 91-02 Protection of the values of Antarctic Specially Managed and Protected Areas (2012).

${ }^{211}$ Druel and others, above n 159, at 44.
} 
shall identify which actions may be pursued by other elements of the ATS to support the specific objectives of the MPA. ${ }^{212}$ For example, as tourism is regulated under the Environment Protocol, an ASMA or ASPA can be adopted to regulate these activities within a MPA.

CCAMLR's conservation mandate can therefore be potentially strengthened, and the overlap encourages the mutually supportive roles of CCAMLR and the Protocol. ${ }^{213}$ This potential is yet to be fully realised. No ASPA with a substantial marine component has been designated in high seas within the CCAMLR area. ${ }^{214}$ Fabra and Gascon state that the Protocol should operate as an "insurance" against any weakening of the environmental objectives of CCAMLR that could put at risk the adequate implementation of the ecosystem approach. ${ }^{215}$ However, requiring CCAMLR's approval for ASPAs or ASMAs that include a marine component can undermine the potential strengthening of integrated management.

Given that CCAMLR members and ATCPs are largely similar (as Namibia and the EU are the only members of CCAMLR that are not also ATCPs), the risk is that the fishing interests prevalent in CCAMLR can move to and influence the operation of the Protocol. The Antarctic and Southern Ocean Coalition commented that States are able to block proposals in CCAMLR more easily than they can in the CEP or at the ATCM due to the mandate to realise their obligations under the Protocol. ${ }^{216}$ The CCAMLR objective of rational use can prevail over the environmental protection objective of the Protocol. Further, the CCAMLR Commission can have input over the management plan, and ensure that fisheries activities are permitted. ${ }^{217} \mathrm{New}$ Zealand's proposal for an expanded ASPA around the Balleny Islands has been the only substantial initiative for a relatively large protected area within the CCAMLR Area outside an EEZ, and the CCAMLR Commission has been unable to endorse this proposal. ${ }^{218}$ The Balleny

\footnotetext{
212 CCAMLR Commission Conservation Measure 91-04 General framework for the establishment of CCAMLR Marine Protected Areas (2011) at [10].

${ }^{213}$ Fabra and Gascon, above n 51, at 592.

214 At 592 and 593.

${ }^{215}$ At 585.

${ }^{216}$ Designation of Marine Protected Areas within the Antarctic Treaty Area (ASOC, ATCM 31, 2008 ) at 7.

${ }^{217}$ Fabra and Gascon, above n 51, at 593 and 594. For example, in 2007, the CCAMLR Commission agreed to endorse a proposal to create an ASMA with a significant marine component in the Southwest Anvers Islands and Palmer Bain. The Commission first sought clarification from the ATCM that the Anvers Island management plan would permit fishing activities within the ASMA.

218 At 593. ASPA 104, designated in 2002, is located in part of the Balleny Islands. The ASPA is a representative sample of the Balleny Islands.
} 
Islands are also within the Ross Sea MPA proposal. ${ }^{219}$ If neither type of protected area can be agreed, the benefit from the unique ATS system to protect the marine environment will not be utilised.

The Protocol can assist in implementing the ecosystem approach more effectively by providing scientific input from Antarctic advisory bodies such as the CEP and the Scientific Committee for Antarctic Research. ${ }^{220}$ Joint CEP/SC-CAMLR workshops are taking place to combine efforts as both bodies overlap in scope on species protection, protected area management, and environmental monitoring. The planning domains from CCAMLR can be coordinated with the rest of the ATS to develop a harmonised regime. ${ }^{221}$ Management of the scientific overlap therefore can avoid duplication, and complement and support selected areas suitable for ASPAs, ASMAs or MPAs. The framework exists for comprehensive coverage for MPAs, but this relies on CCAMLR members also fulfilling their obligations under the Antarctic Treaty and Environment Protocol, as required under CCAMLR Article III to V.

(a) Problem of fishing in ASMAs and ASPAs

The region also faces similar teething problems with coordination as the North-East Atlantic. The CCAMLR Commission noted that krill fishing had occurred in 2010 by CCAMLR members (two vessels conducted 31 hauls) and in 2012 (three vessels conducted 121 hauls) in ASPA No. 153 in the Eastern Dallmann Bay. ${ }^{22}$ The management plan of the ASPA, which is approximately 676 square kilometres, does not allow harvesting as a permitted activity. ${ }^{223}$

The Commission agreed that the fishing occurred due to a lack of awareness of the requirements of the management plan, and approved Conservation Measure 91-02 (2012)

\footnotetext{
219 "Ross Sea region Marine Protected Area: Revised Proposal" New Zealand Ministry of Foreign Affairs and Trade <www.mfat.govt.nz/ross-sea-mpa $>$.

${ }^{220}$ Fabra and Gascon, above n 51, at 585.

${ }^{221}$ At 594.

${ }^{222}$ CCAMLR Commission Report of the Thirty-First Meeting of the Commission, October-November 2012, CCAMLR-XXXI at [5.66].

${ }^{223}$ Scientific Committee for the Conservation of Antarctic Marine Living Resources Report of the Thirty-First Meeting of the Scientific Committee, October 2012, SC-CAMLR-XXXI at [5.65].
} 
which recognised the importance of ASMAs and ASPAs. ${ }^{224}$ Noting the concern that "potential harvesting in ASPAs and ASMAs could jeopardise the high seas scientific value of the longterm ecosystem studies being carried out in these areas". The Conservation Measure recognises the need for more informative and timely communication between the ATCM and CCAMLR with regard to the publication and availability of management plans. It also imposes the duty on each contracting party to ensure their fishing vessels are aware of the location and relevant management plans of all designated ASPAs and ASMAs containing marine areas. ${ }^{225}$

\section{Are Southern Ocean Organisations in a Better Position to Manage Activities?}

States operating in the Southern Ocean are in a better legal position to have comprehensive oversight of activities within MPAs. The ability to rely on the Protocol to fill gaps for regulatory activities that CCAMLR does not have competence over is an important part of the ATS framework. It is significant that CCAMLR and the CEP have decided that CCAMLR is the lead authority for MPAs. The ability for CCAMLR to submit a management plan for a proposed ASPA and ASMA is a unique tool, and can allow for greater integrated management. The potential problem is that CCAMLR's requisite approval for the designation of an ASPA or ASMA with a marine component can result in fisheries interests coming in through the backdoor to undermine the Environment Protocol's objectives. If that is overcome, the Southern Ocean has a unique ability to manage MPAs.

The North-East Atlantic Ocean has a less integrated framework, but OSPAR is working towards building cooperative arrangements with the relevant bodies to overcome sectoral issues. OSPAR is reliant on NEAFC and its member States to manage the MPAs. Through the Memorandum of Understanding, it can have more input into NEAFC decisions and become more involved in monitoring fisheries activities in the MPAs. The partial alignment of OSPAR MPAs and NEAFC closure areas illustrates that if the institutional overlap is not managed early on, the result can be patchy protection. Avoiding duplication of efforts is important, and both regions have placed importance on sharing science as a means to fulfil conservation objectives.

\footnotetext{
${ }^{224}$ CCAMLR Commission Conservation Measure 91-02 Protection of the values of Antarctic Specially Managed and Protected Areas (2012).

${ }^{225}$ Ibid.
} 


\section{The Role of RFMOs for Compliance and Enforcement}

There is little doubt that fishing activities are one of the major threats to marine biodiversity. This section explores how CCAMLR and NEAFC, and RFMOs in general can focus on compliance and enforcement to support the management of MPAs. Lessons about enforcement and compliance can be drawn from the efforts in international fisheries more generally, as MPA measures may be similar to general RFMO measures although the goals may be slightly different. ${ }^{226}$ If States do not ensure compliance with the rules of the MPA, the purpose of the protected area may be undermined. ${ }^{227}$ Compliance by member States and nonmember States of their obligations is crucial, if this is unsuccessful, enforcement measures may become necessary. Without this the MPA runs the risk of being a labelled a paper park; with a noble name but no real protection. ${ }^{228}$

\section{A General Existing Measures}

RFMOs are the main organisations in ABNJ that have power to create and enforce fisheries measures. ${ }^{229}$ OSPAR relies on its member States and other organisations to undertake control and enforcement activities in the MPAs, the role of NEAFC is of paramount importance. Similarly, CCAMLR is the organisation in the Southern Ocean with competence to regulate fisheries activities. The UN Fish Stocks Agreement represents a significant development and provides the backdrop for most enforcement activities. It requires that States who seek to have access to the fishery must follow the conservation and management measures adopted by the relevant RFMO. ${ }^{230}$ Measures adopted for MPAs, either if the RFMO has designated the MPA or where they have established measures to support the management of a MPA, can fall within this principle.

${ }^{226}$ Joanna Mossop "High Seas Marine Protected Areas: Unfulfilled Promise or Impossible Premise?" in A Costi and Y-L Sage (eds) Environmental Law in the Pacific: International and Comparative Perspectives (New Zealand Association of Comparative Law and Association de Legislation Comparee des Pays du Pacifique, Wellington, 2005) at 173 .

${ }^{227}$ At 158.

${ }^{228}$ Kristina Gjerde and Anna Rulska-Domino "Marine Protected Areas beyond National Jurisdiction: Some Practical Perspectives for Moving Ahead" (2012) 27 IJMCL 351 at 357.

${ }^{229}$ Recommended Best Practices for Regional Fisheries Management Organizations (The Royal Institute of International Affairs, Chatham House, London, 2007) at 1.

${ }^{230}$ UN Fish Stocks Agreement, art 8(2). 
Compliance and enforcement is most commonly achieved through monitoring, control and surveillance (MCS). ${ }^{231}$ Common MCS measures include observers on fishing vessels, boarding and inspection, a catch documentation scheme to verify the legality of catches before allowing landing or imports, ${ }^{232}$ and vessel monitoring schemes (VMS) to monitor and verify the location of fishing vessels. ${ }^{233}$ As well as assisting enforcement, VMS can aid compliance by including boundaries of MPAs and issuing automatic warnings to vessels when boundaries are approached. ${ }^{234}$

MCS is simpler where the MPA coincides with an area that is closed to fishing. ${ }^{235}$ For example, as the South Orkney Islands MPA prohibits all forms of fishing (aside from scientific fishing) this provides a straightforward way of ensuring compliance and enforcement. More complex is the Ross Sea and East Antarctic proposals which include different levels of protection. Multiple use zones can required sophisticated MCS programmes to determine if activities are compliant with specific regulations. ${ }^{236}$ Higher levels of compliance are arguably achieved better where the management plan is simple. ${ }^{237}$ However, compromise to designate MPAs in the first place may require multiple uses of the area. The primary challenge will be coordination of MCS efforts for MPAs to ensure no enforcement gaps are created. For example, the dual regimes that apply in the water column and seabed/subsoil of OSPAR MPAs which overlap with NEAFC closure areas and the Portuguese extended continental shelf requires coordinated MCS efforts.

B The Problem of Non-Parties: Is there an Enforcement Right?

The default principle of exclusive flag State jurisdiction requires flag State enforcement if a vessel breaches measures. This principle has flaws, especially if the vessel operates as a

${ }^{231}$ Denzil Miller, Natasha Slicer and Quentin Hanich "Monitoring, control and surveillance of protected areas and specially managed areas in the marine domain" (2013) 39(1) Marine Policy 64 at 65.

${ }^{232}$ CCAMLR pioneered this scheme for toothfish. See further Fabra and Gascon, above n 51, at 590.

${ }^{233}$ Sara Monterio, Xavier Vazquez and Ronan Long "Improving fishery law enforcement in marine protected areas" (2010) 1(1) Aegean Review of the Law of the Sea and Maritime Law 95 at 105.

${ }^{234}$ Alistair Hobday and others "Missing Dimension- Conserving the largest habitat on Earth: protected areas in the pelagic ocean", above n 4, at 363 .

${ }^{235}$ Monterio, Vazquez and Long, above n 233, at 101.

${ }^{236}$ Miller, Slicer and Hanich "Monitoring, control and surveillance of protected areas and specially managed areas in the marine domain", above n 231, at 69.

${ }^{237}$ Monterio, Vazquez and Long, above n 233, at 101. 
flag of convenience. Problems arise from insufficient or inaccurate data reporting, lack of enforcement capability, and intransigence amongst other things. ${ }^{238}$ Illegal, Unreported and Unregulated (IUU) fishing is the umbrella term used to describe fishing by member and nonmember States to the RFMO in breach of measures. IUU fishing can increase with the designation of MPAs as these areas are now regulated. Designation can compound the incentive to flag or re-flag vessels to non-RFMO flag States to avoid the applicability of regulations. ${ }^{239}$ This is particularly a justified concern for CCAMLR given the number of nonCCAMLR members involved either as flag States in fishing for, or as port States in the trade of IUU caught toothfish. ${ }^{240}$

In the absence of a global framework, especially detailing the relationship with third States, designation and regulation of activities of MPAs in ABNJ lack legitimacy. ${ }^{241}$ Interference with the high seas freedoms of third States is unjustifiable, ${ }^{242}$ reflecting the wider international law position that States can only be bound by treaties they have signed. ${ }^{243}$ Enforcement measures can therefore only be taking against contracting parties to the relevant Convention.

The way to indirectly address the problem is to allow some enforcement action through the relevant RFMO for breaches of fisheries activities within the MPA. The UN Fish Stocks Agreement allows only vessels fishing in accordance with conservation and management measures adopted by RFMOs to exercise their freedom free from interference as they have discharged their duty to cooperate. ${ }^{244}$ Membership to a RFMO, or at least agreeing to play by the rules, is the sine qua non of access to a fishery as per Article 8(4) of the UN Fish Stocks Agreement. ${ }^{245}$ Under Article 17(4), members of RFMOs are able to take measures consistent with international law and the UN Fish Stocks Agreement to deter the activities of vessels

\footnotetext{
${ }^{238}$ Miller, Sabourenkov and Ramm "Managing Antarctic Marine Living Resources: The CCAMLR Approach", above $\mathrm{n} 49$, at 353 .

${ }^{239}$ At 353 and 354.

240 At 354 .

${ }^{241}$ Molenaar "Managing Biodiversity in Areas Beyond National Jurisdiction”, above n 208, at 106.

${ }^{242}$ Unless the interference is based on rights under customary international law. See further Molenaar "Managing Biodiversity in Areas Beyond National Jurisdiction", above n 208, at 106.

${ }^{243}$ Vienna Convention on the Law of Treaties, art 34. See also UNCLOS, art 311(2).

${ }^{244}$ Rosemary Rayfuse Non-Flag State Enforcement in High Seas Fisheries (Martinus Nijhoff Publishers, Leiden, 2004) at 42.

${ }^{245}$ At 44 .
} 
which undermine the effectiveness of RFMOs. ${ }^{246}$ This is by no means a silver bullet. First, the duty to cooperate will only apply to States party to the UN Fish Stocks Agreement, as it is doubted that the duty to cooperate or refrain is regarded as customary international law binding on all States. ${ }^{247}$ Second, deciding on conservation measures is difficult in RFMOs. Agreement has been reached that bottom trawling is not an acceptable activity in a MPA, but agreement on measures for pelagic fishing are not so forthcoming. The issue is whether more generally RFMOs are able to balance keeping fisheries areas open with protecting marine biodiversity.

Provided this agreement can be reached in the RFMO, enforcement activities against third States is possible, for example through measures identified in the UN Food and Agriculture Organisation (FAO) International Plan of Action to Prevent, Deter and Eliminate IUU Fishing. The international community continues to develop creative legal responses to overcome the shortcomings from adherence to exclusive flag State jurisdiction. ${ }^{248}$ For example, NEAFC and CCAMLR presume that if flag State consent is refused, the vessel is acting as an IUU vessel and can be added to a blacklist with certain consequences such as denial of port access. $^{249}$ Although port State measures can exert a strong influence on the conduct of nonparty flag States and their vessels, most other measures, however, are only binding on State parties to the relevant treaty. ${ }^{250}$ The reliance on RFMOs to use their general fisheries measures is the best option currently available to provide an incentive for compliance and a means to enforce MPA measures.

\section{Guidance and Issues for Other Regional Organisations}

Two different models to create MPAs have been illustrated in this paper. CCAMLR fits within the ATS which is a sophisticated structure, unlikely to be replicated in any other region.

\footnotetext{
${ }^{246}$ At 45.

${ }^{247}$ Rosemary Rayfuse "The Anthropocene, Autopoiesis and the Disingenuousness of the Genuine Link: Addressing Enforcement Gaps in the Legal Regime for Areas Beyond National Jurisdiction” in Erik J Molenaar and Alex Oude Elferink (eds) The International Legal Regime of Areas Beyond National Jurisdiction: Current and Future Developments (Martinus Nijhoff Publishers, Leiden, 2010) at 175. Note also that signature to the UN Fish Stocks Agreement is significantly less than UNCLOS. Many large fishing States have not signed the Agreement.

${ }^{248}$ At 179.

${ }^{249}$ Fabra and Gascon, above n 51, at 590.

${ }^{250}$ Rayfuse "The Anthropocene, Autopoiesis and the Disingenuousness of the Genuine Link: Addressing Enforcement Gaps in the Legal Regime for Areas Beyond National Jurisdiction”, above n 247, at 179.
} 
CCAMLR is an outlier given the special status of the Antarctic for research and peaceful purposes. Some of the designation and management issues, however, can be useful for other organisations to learn from. The North-East Atlantic model is able to be replicated in other regions where a RSC overlaps with a RFMO. This final section will distill general themes outlined in this paper for other regional organisations who seek to create and manage MPAs.

\section{A Other Regional Efforts and Trends}

Regional organisations, either RFMOs or RSCs, are currently the best forum to designate and manage MPAs. Current efforts by other regional organisations are focused in the Mediterranean Sea and Sargasso Sea. A number of RSCs, including the Convention for the Protection of Natural Resources and Environment of the South Pacific (SPREP Convention) also have the potential for the creation of MPAs. RSCs, however, cannot operate alone. RFMOs are the best vehicle to steer fisheries management efforts and RFMOs can develop enforcement measures. There are 44 regional fisheries bodies worldwide, 20 of which are RFMOs as they have a management mandate as well as an advisory mandate. ${ }^{251}$ RFMOs have started to integrate the protection of marine biodiversity as a management objective into their framework conventions and various decisions. ${ }^{252}$ For example, the newly formed South Pacific Regional Fisheries Management Organisation (SPRFMO) has an explicit mandate to protect vulnerable marine ecosystems. ${ }^{253}$ If RFMOs undertake their area-based management measures in concert with other regional organisations (where available) focused on the conservation of the marine environment and biological diversity, comprehensive management can be developed. ${ }^{254}$

\section{B Are RFMOs or RSCs the Best Forum?}

There are different strengths and weaknesses depending on the type of regional organisation to designate and manage a MPA in ABNJ. On the one hand, RFMOs with an environmental protection mandate to apply the ecosystem approach are in a stronger position to designate and manage MPAs effectively. RFMOs have a recognised status under UNCLOS and the UN Fish Stocks Agreement, and significant conservation objectives attach to the

\footnotetext{
${ }^{251}$ Drankier, above n 157, at 325.

${ }^{252}$ Druel and others, above n 159 , at 87.

253 SPRFMO, art 20(1)(d).

${ }^{254}$ Drankier, above n 157, at 329.
} 
operation of RFMOs. ${ }^{255}$ Under the Fish Stocks Agreement, parties have a duty to ensure longterm sustainability, protect biodiversity in the marine environment, apply the precautionary approach, assess the impacts of fishing, and adopt conservation measures for species belonging to the same ecosystem. ${ }^{256}$ Some RFMOs have a strengthened ability to support MPAs. For example, CCAMLR, NEAFC, the General Fisheries Commission for the Mediterranean, and the South East Atlantic Fisheries Organisation (SEAFO) conventions explicitly refer to the possibility to establish closed fishing areas. ${ }^{257}$ It is important that these closed fishing areas provide for long-term protection to meet the conservation objectives of MPAs, and are not just a short-term temporary measure.

There is, however, a concern that if a mandate to manage fisheries and to protect the environment are merged in the one organisation (as in CCAMLR) fisheries will take priority over environmental issues. ${ }^{258}$ The inability to make a decision to prioritise conservation can be problematic, seen by the failure to adopt the Ross Sea and East Antarctic proposals. However, merging the mandate to create MPAs into a 'hybrid' RFMO/RSC structure has the advantage of enabling an earlier decision-making process as only one organisation is involved. ${ }^{259}$ Even so, activities such as mining, tourism and scientific research may fall outside the RFMOs parameters. Regulations through RFMOs addressing the impacts of fishing alone are likely to be insufficient to conserve an ecosystem as a whole. ${ }^{260}$ These regulatory gaps require filing through cooperation and coordination with other relevant regional bodies.

On the other hand, a RSC has a stronger environmental protection mandate and oversight over a wider range activities. Its competence, however, is likely to exclude measures over fisheries activities. RSCs are therefore required to cooperate and be supported by a RFMOs, however, as seen with OSPAR and NEAFC this may not be as timely and effective to support the MPA. If successful, the cumulative effect of cooperation between these institutions (as well as the IMO and ISA) can help build a MPA with multiple layers of protection. The RSCs can become a 'hub' and support other organisations to coordinate

\footnotetext{
${ }^{255}$ Mossop, above n 266, at 171.

${ }^{256}$ Reeve, Rulska-Domino and Gjerde “The Future of High Seas Marine Protected Areas", above n 38, at 274. See UN Fish Stocks Agreement, arts 5 and 6.

${ }^{257}$ Drankier, above n 157, at 339.

${ }^{258}$ Druel and others, above n 159 , at 87.

${ }^{259}$ At 87.

${ }^{260}$ Reeve, Rulska-Domino and Gjerde “The Future of High Seas Marine Protected Areas”, above n 38, at 268.
} 
activities, such as aligning IMO Particularly Sensitive Sea Areas for shipping with fisheries closure areas and MPAs. Coordination between these bodies is important to ensure synergistic efforts rather than impractical measures.

\section{Importance of Institutional Overlap}

The North-East Atlantic is a useful model because of the institutional overlap which is imperative for integrated management. It can also be replicated in a number of regions. Geographic coverage is extremely important so that measures can be complementary in the same area. The benefit from a membership overlap is that member States represented in both organisations can coordinate measures. Both organisations should also have a conservation and protection mandate, even if it is not over the same activities.

It is critical that this overlap is identified and managed early. Two examples will be briefly discussed to illustrate the common problems regional organisations face. MPAs in the Mediterranean Sea are placed within the so-called 'Barcelona system', which is composed of several treaties relating to the protection of the marine environment including marine biodiversity. ${ }^{261}$ Strengthening links with other international organisations is greatly encouraged, but in reality is limited to ad hoc coordination with the General Fisheries Commission for the Mediterranean (GFCM), while no cooperation agreements have been concluded with other international bodies (such as the IMO). ${ }^{262}$ The Barcelona Convention does not specifically refer to the regulation of fisheries activities. ${ }^{263}$ MPAs situated partly or wholly in the high seas are to be added to the Specially Protected Areas of Mediterranean Importance (SPAMI) List. ${ }^{264}$ The SPAMI List includes 33 sites, with the French-ItalianMonegasque Sanctuary for Marine Mammals (Pelagos Sanctuary) being the only site established partially in the high seas to date. Some management measures have been agreed by the parties, with the GFCM closing the Pelagos Sanctuary to fishing with towed dredges and

\footnotetext{
${ }^{261}$ Tanaka "Reflections on High Seas Marine Protected Areas: A Comparative Analysis of the Mediterranean and the North-East Atlantic Models", above n 44, at 305. Large expanses of the Mediterranean Sea located beyond these zones remain the high seas. This is likely to be a transient condition, when Mediterranean coastal States declare their EEZ, the high seas will disappear from the Mediterranean.

262 Drankier, above n 157, at 340.

263 At 324.

${ }^{264}$ At 339.
} 
bottom trawl nets in 2006. ${ }^{265}$ Drankier calls for the Sanctuary to have a stronger integration with the objectives of other organisations, as well as a stronger mandate and competences to establish more effective management actions. ${ }^{266}$

The second example is in the South West Pacific; an area where the governance framework is highly fragmented. ${ }^{267}$ The SPREP Convention is intended to be a comprehensive, umbrella agreement for the protection, management and development of the marine and coastal environment. ${ }^{268}$ This is very similar to OSPAR. As such, it allows parties to take appropriate measures to establish protected areas, and prohibit or regulate any activity likely to have adverse effects on species, ecosystems or biological processes. ${ }^{269}$ Article 14 so far has not been used to protect areas in ABNJ. ${ }^{270}$ The SPREP Convention allows action to be taken to regulate or prohibit "any human activity", however, it is likely that these decisions will be deferred to the competent RFMO in the Convention area. ${ }^{271}$ Therefore, there must be cooperation and coordination between the Western Central Pacific Fisheries Commission (WCPFC) which manages highly migratory species, as well as the SPRFMO Commission. The WCPFC has closed two of the four high seas pockets in the SPREP Convention area to purse seine fishing of tuna. ${ }^{272}$ The SPRFMO Commission also has the competence to adopt conservation and management measures to protect the habitats and marine ecosystems from the impacts of fishing, and prevent significant adverse impacts on vulnerable marine ecosystems. ${ }^{273}$ Cooperation and coordination between these organisations can result in comprehensive protection for any MPA; but this is yet to be fully realised.

\section{$1 \quad$ Management of the Overlap}

A clarification of competencies through a memorandum of understanding, as carried out by OSPAR and NEAFC, or a similar agreement is important in areas where the North-East

\footnotetext{
265 At 322.

266 At 322.

${ }^{267}$ Druel and others, above n 159, at 78 .

${ }^{268}$ At 63.

269 SPREP Convention, art 14.

${ }^{270}$ Druel and others, above n 159, at 65 .

${ }^{271}$ At 77.

272 At 65 and 66. This measure was lifted in 2012 to authorise vessels from the Philippines to fish in the pockets.

${ }^{273}$ SPRFMO Convention, art 1(f).
} 
Atlantic model can be replicated. This will spell out who is the lead organisation and what the role of each organisation is. There must be mechanisms to cooperate through meetings, a common science platform, assessments of protected areas, and national level coordination. ${ }^{274}$ Agency participation must be coordinated at a national level to ensure a consistent approach, and that measures taken in one organisation can be supported in another organisation represented by the same State. If cooperation is established early, for example the alignment of OSPAR's MPAs and NEAFC's closure areas, it will allow for synergistic protection of vulnerable ecosystems.

Shared science plays an important role for OSPAR and NEAFC through the ICES. A concrete scientific basis can be established if both organisations operate from the same scientific values and data, and this way ensures that designation and management is left to political and diplomatic efforts. CCAMLR and the CEP have formed joint workshops to allow cooperation between their scientific bodies, which other organisations too should seek to establish. A duplication of efforts, especially where resources are limited, can be avoided. A positive international development would also be global agreement on the scientific selection criteria for the identification of potential MPAs, such as the Ecologically or Biologically Significant Marine Areas criteria developed by the Conference of Parties to the CBD. ${ }^{275}$ This would be especially helpful for coordinating the identification processes of protected areas between sectoral organisations to minimise conflicts over which areas merit protection. ${ }^{276}$ The difficulty NEAFC and OSPAR face over the Josephine Seamount MPA, as a vulnerable marine ecosystem, illustrates the difficulties in achieving consensus in the absence of such framework.

\section{Limitations of the North-East Atlantic Model}

The difficulty also lies with RFMO members reaching agreement on conservation and management measures to create and support the MPA. The UN General Assembly can play a leading role here to provide the motivation and impetus for action to mitigate the impacts of fishing on marine ecosystems. While these resolutions are generally considered to be soft law, when properly formulated they can be very compelling, as evidenced by the indefinite

\footnotetext{
${ }^{274}$ Kvalvik, above n 134, at 42.

275 Drankier, above n 157, at 343.

${ }^{276}$ At 343.
} 
moratorium on large scale drift net fishing adopted in 1990-1992. ${ }^{277}$ UN General Assembly Resolutions 61/105 in 2006 and 64/72 in 2009 called upon States and RFMOs with the competence to regulate bottom fisheries, to adopt and implement key measures such as closure areas. $^{278}$ Protection of bottom fisheries, however, is not the only threat to MPAs. Similar resolutions for pelagic fisheries are long overdue. ${ }^{279}$

As stated earlier, another concern is that fishing interests will prevail over conservation in RFMO decision-making. Where a RSC relies on a RFMO to implement necessary fisheries measures, the protection of a MPA can be seriously undermined. Finding the balance between economic interests and benefits from conservation is difficult and common to all RFMOs. Even between States who recognise the importance of conservation, problems can arise as to how best to protect marine biodiversity as was seen in the joint US and New Zealand Ross Sea proposal. Multipurpose use MPAs can accommodate these interests. For example, small seasonal catches may be allowed instead of a complete no-take area. This may not be the optimal outcome for affording the highest level of protection to the area, and it may be difficult to measure compliance; but there needs to be an incentive for States to cooperate on establishing MPAs. If States believe fishing activities are being taken away they, and their interest in this overlooked, they have little to gain from cooperation. Given the challenge most organisations face with consensus voting, some balance between these two values must be addressed within the MPA framework without excluding contentious areas that are vital for ecological considerations.

\section{$1 \quad$ What if no regional organisations exist?}

Many ABNJ do not benefit from regional rules for the protection of biodiversity and therefore fall outside of the North-East Atlantic model (and the CCAMLR/ATS model). ${ }^{280}$ RFMO coverage gaps in ABNJ is not uncommon, as seen in the figure below. Many RSCs also only cover areas within national jurisdiction.

\footnotetext{
277 Jeff A. Ardron and others "The sustainable use and conservation of biodiversity in ABNJ: What can be achieved using existing international agreements?” (2014) 49 Marine Policy 98 at 102. 


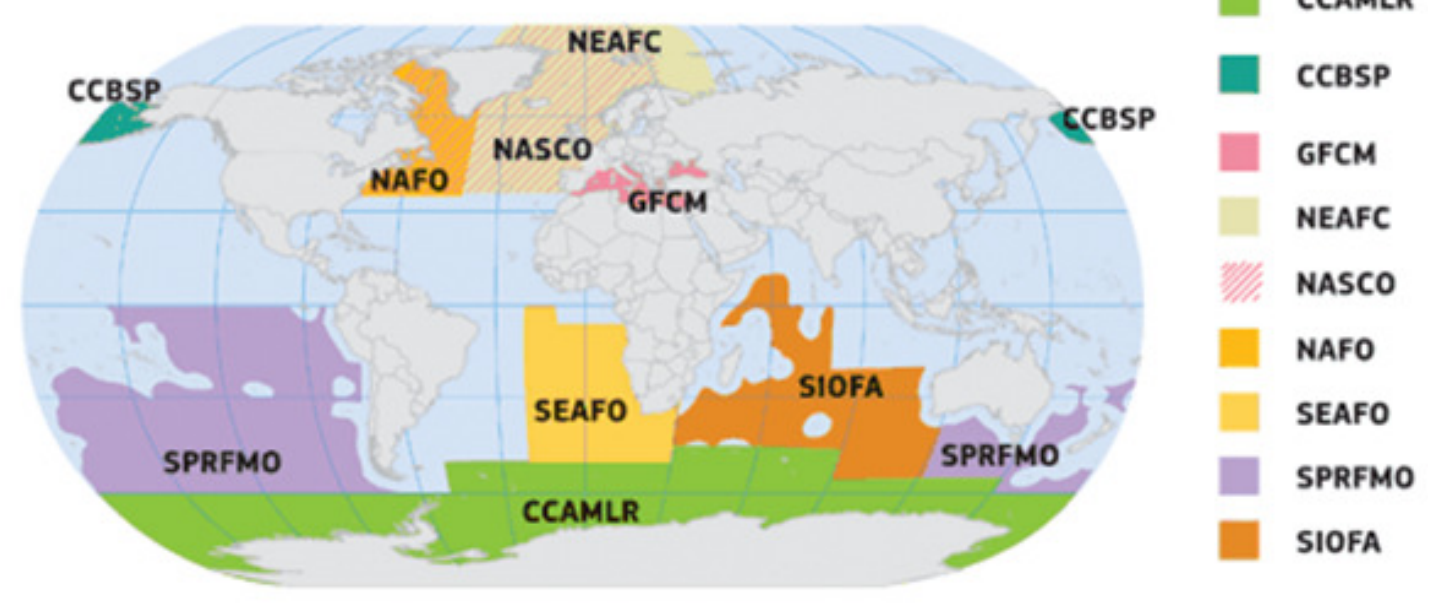

The Sargasso Sea is a prime example of this regulatory gap. The majority of the Sargasso Sea is located in ABNJ where there is no regional environmental treaty covering the area, nor is there a regional fisheries treaty applicable to the whole area for non-tuna species. ${ }^{282}$ The management of this ecosystem is strikingly different from the Southern Ocean and NorthEast Atlantic Ocean.

The Sargasso Sea Alliance was formed from a range of international partners led by the Government of Bermuda, supported by the United Kingdom. ${ }^{283}$ The Alliance seeks to use exiting sectoral organisations with relevant competences (such as the IMO and ISA) and encourage these organisations to adopt new protection measures. ${ }^{284}$ The Sargasso Sea Alliance has aligned with the Northwest Atlantic Fisheries Organisation (NAFO) for the small regulatory area overlap. ${ }^{285}$ NAFO is currently considering whether closure areas are required to protect foraging areas or habitats that can be impacted by different types of fishing in the Sargasso Sea. ${ }^{286}$ The International Commission for the Conservation of Atlantic Tuna (ICCAT) also covers the area, and the Alliance has established cooperation with ICCAT, but single species RFMO are unlikely to result in comprehensive coverage for MPAs. The UN Fish

\footnotetext{
${ }^{281}$ European Commission "Regional fisheries management organisations (RFMOs)" <www.ec.europa.eu>.

282 Julien Rochette and others "The regional approach to the conservation and sustainable use of marine biodiversity in areas beyond national jurisdiction", above n 128, at 114 .

${ }^{283}$ As Bermuda is a British overseas territory.

${ }^{284}$ David Freestone and Kate Morrison “The Sargasso Sea: Seeking to Protect the Sargasso Sea” 201227 IJMCL 647 at 652.

${ }^{285}$ Druel and others, above n 159 , at 81.

${ }^{286}$ Sargasso Sea Commission "Northwest Atlantic Fisheries Organization" <www.sargassoalliance.org $>$.
} 
Stocks Agreement requires that where no RFMO exists with responsibility for a particular straddling or highly migratory fish stock, States are obliged to cooperate to establish one or to establish 'other appropriate arrangements' to ensure conservation and management of the stock concerned and to participate in the work of these organisations or arrangements. ${ }^{287}$ The lesson from the Sargasso Sea is that establishing protective measures is difficult where organisations have limited history cooperating together, different competencies, and different scientific criteria. Further, processes are extremely time and labour intensive, and the lack of coordination between the various sectors highlights the silo mentality of national governments and the international fora. ${ }^{288}$ The potential exists, but relies on political will and resources.

\section{E $\quad$ Capacity Issues for Developing States}

At a general level in ABNJ, insufficient monitoring and surveillance capacity, along with weak enforcement of activities is a main impediment to sustainable use and conservation of marine biodiversity. ${ }^{289}$ The issue of capacity, to ensure effective compliance and enforcement, is problematic in many regions around the world. For example, the level of IUU fishing in the South West Pacific, especially in the four high seas pockets, used as a refuge for vessels fishing illegally in the EEZs of Pacific coastal States has been documented. ${ }^{290}$ Possible MPA management by SPRFMO or WCPFC requires a concerted effort to combat illegal fishing. Although RFMOs may rely on the UN Fish Stocks Agreement to exclude nonmembers from fishing in the MPA, the RFMO must also have the capacity to follow through on the management plans.

Given the time and resource intensive efforts undertaken so far in the Southern Ocean, North-East Atlantic, Sargasso Sea and Mediterranean Sea; regional organisations can enable the designation of MPAs where the requisite human capacity exists. ${ }^{291}$ While a regional approach is best, comprehensive protection on a consistent basis across $\mathrm{ABNJ}$ requires scientific, legal and technical capacity, and MPAs may therefore only be established in regions

\footnotetext{
${ }^{287}$ Rayfuse Non-Flag State Enforcement in High Seas Fisheries, above n 244, at 43.

${ }^{288}$ David Freestone and others "Can existing institutions protect biodiversity in areas beyond national jurisdiction? Experiences from two on-going processes” (2014) 49 Marine Policy 167 at 172.

${ }^{289}$ Reeve, Rulska-Domino and Gjerde “The Future of High Seas Marine Protected Areas", above n 38, at 267.

${ }^{290}$ Druel and others, above n 159, at 73.

${ }^{291}$ Reeve, Rulska-Domino and Gjerde “The Future of High Seas Marine Protected Areas”, above n 38, at 288.
} 
surrounded by developed countries. ${ }^{292}$ A geographic gap in coverage in regions with coastal States as developing countries will not contribute to comprehensive global MPA coverage. Potentially, a global agreement could support action at the regional level by creating a mechanism for financial and technical assistance to build capacity and facilitate developing country participation. ${ }^{293}$ Alternatively, the UN Environmental Programme can also facilitate building options and capacity for comprehensive coverage. ${ }^{294}$

\section{Conclusion}

The issues facing the two regions in designating and managing MPAs in ABNJs differ on some aspects, but there are also commonalities. The Southern Ocean has the best management framework to coordinate the designation and implementation of MPAs. The unique competence of CCAMLR as a hybrid combining aspects of both a RFMO and RSC allows this potential for greater protection. Whereas the North-East Atlantic region contains sectoral organisations that must cooperate and coordinate to allow integrated management as the path forward to manage MPAs. Though both organisations have distinct frameworks, they face similar issues with managing institutional overlap, requiring better communication and shared science amongst the relevant bodies. The CCAMLR Commission's cooperation with the CEP, as the other ATS instrument, has sought to clarify who is to take the lead role in designating MPAs. CCAMLR now needs to agree on the proposals for the Ross Sea and East Antarctic MPAs to be on the road to create a network of MPAs. OSPAR has created a representative network of MPAs in the Wider Atlantic region, though it faced some challenges through overlapping extended continental shelf claims, it has been able to establish these MPAs with the cooperation of member States with similar interests in protection. The focus is now on management of OSPAR MPAs. The partial alignment of NEAFC closure areas with OSPAR MPAs serves as a reminder for other regional organisations to identify and manage institutional overlaps at the earliest opportunity.

The lessons for future regional organisations can be premised on the OSPAR/NEAFC model to work within a RFMO/Regional Seas framework to ensure comprehensive protection

\footnotetext{
292 At 288.

${ }^{293}$ Gjerde and Rulska-Domino "Marine Protected Areas beyond National Jurisdiction: Some Practical Perspectives for Moving Ahead", above n 228, at 373. ${ }^{294}$ At 362.
} 
of MPAs. The main drawback from this model is the potential inability of RFMOs to make a decision on fisheries activities within the protected areas to maximise conservative efforts. The benefit of RFMO inclusion is the ability to impose some protective measures against third States who undermine MPA conservative objectives. This model is limited to areas where a regional environmental treaty body and non-tuna RFMO exists.

The benefit of a global implementing agreement would be some form of agreement on scientific criteria to establish a MPA, and ensuring MPA measures can be enforced against third States. ${ }^{295}$ Even if there was a global implementing agreement, this would still have to be fleshed out on the regional level and supported by national action. The Bonn report on the management of MPAs in ABNJ summarised the idea as "management of MPAs in ABNJ should be globally coordinated, regionally driven and subject to the responsibility of States". 296 The two models are predicated on member States being represented in the different organisations pushing for protection efforts, and then supporting efforts to carry out management. Political will and capacity is imperative at the regional level to cooperate and coordinate efforts to designate and implement MPAs in ABNJ. Ultimately, States must continue to recognise the importance of working through regional organisations to protect and conserve the marine environment and biodiversity.

\footnotetext{
295 Druel and others, above n 159, at 88.

${ }^{296}$ International Seminar on Conservation and Sustainable Use of Marine Biodiversity beyond National Jurisdiction: Summary Report (IUCN and German Federal Agency for Nature Conservation, Bonn, December 2011) at 32. [Bonn report].
} 


\section{Bibliography}

\section{A Conventions and Treaties}

$1 \quad$ International Instruments

Convention on Biological Diversity 1760 UNTS 79 (opened for signature 5 June 1992, entered into force 29 December 1993). [CBD].

United Nations Agreement for the Implementation of the Provisions of the United Nations Convention on the Law of the Sea 10 December 1982 Relating to the Conservation and Management of Straddling Fish Stocks and Highly Migratory Fish Stocks 2167 UNTS 88 (opened for signature on 4 August 1995, entered into force 11 December 2001). [UN Fish Stocks Agreement].

United Nations Convention on the Law of the Sea 1833 UNTS 3 (opened for signature 10 December 1982, entered into force 16 November 1994). [UNCLOS].

\section{Regional Instruments}

Antarctic Treaty 402 UNTS 71 (opened for signature 1 December 1959, entered into force 23 June 1961).

Convention for the Protection of the Marine Environment and the Coastal Region of the Mediterranean, amended and renamed 10 June 1995, 1102 UNTS 27 (opened for signature 16 February 1976, entered into force 12 February 1978). [Barcelona Convention].

Convention for the Protection of the Marine Environment of the North-East Atlantic 2354 UNTS 67 (opened for signature 22 September 1992, entered into force 25 March 1998). [OSPAR].

Convention for the Protection of the Natural Resources and Environment of the South Pacific Ocean 26 ILM 38 (opened for signature 25 November 1986, entered into force 22 August 1990). [SPREP Convention].

Convention on Future Multilateral Co-operation in the North-East Atlantic Fisheries 1285 UNTS 129 (opened for signature 18 November 1980, entered into force 17 March 1982). [NEAFC Convention].

Convention on the Conservation of Antarctic Marine Living Resources 1329 UNTS 47 (opened for signature 20 May 1980, entered into force 7 April 1982). [CCAMLR].

Convention on the Conservation and Management of High Seas Fishery Resources in the South Pacific Ocean [2012] ATS 28 (opened for signature 1 February 2010, entered into force 24 August 2012). [SPFRMO].

Protocol Concerning Specially Protected Areas and Biological Diversity in the Mediterranean 2102 UNTS 203 (opened for signature 10 June 1995, entered into force 12 December 1999). [SPAMI]. 
Protocol on Environmental Protection to the Antarctic Treaty 30 ILM 1455 (opened for signature 4 October 1991, entered into force January 14 1998). [Environment Protocol].

\section{B United Nations Material}

Background document for the High Seas MPAs regional approaches and experience side event at the $12^{\text {th }}$ UNEP Global Meeting of the Regional Seas Conventions and Action Plans, 20 September 2010.

CBD Seventh Meeting of the Conference of the Parties to the Convention on Biological Diversity (2004).

CBD Tenth Meeting of the Conference of the Parties to the Convention on Biological Diversity (2010).

Corrigan, Colleen and Kershaw, Francine Working Towards High Seas Marine Protected Areas: Assessment of Progress Made and Recommendations for Collaboration (UNEPWorld Conservation Monitoring Centre, October 2008).

Sustainable fisheries, including through the 1995 Agreement for the Implementation of the Provisions of the United Nations Convention on the Law of the Sea of 10 December 1982 relating to the Conservation and Management of Straddling Fish Stocks and Highly Migratory Fish Stocks, and related instruments GA Res A/Res/61/105 (2006).

Sustainable fisheries, including through the 1995 Agreement for the Implementation of the Provisions of the United Nations Convention on the Law of the Sea of 10 December 1982 relating to the Conservation and Management of Straddling Fish Stocks and Highly Migratory Fish Stocks, and related instruments GA Res A/Res/64/72 (2009).

World Summit on Sustainable Development Plan of Implementation of the World Summit on Sustainable Development, 4 September 2002, A/CONF.199/20.

\section{Regional Organisations}

$1 \quad$ CCAMLR Documents

A proposal for the establishment of a Ross Sea Region Marine Protected Area, Delegations of New Zealand and the USA, 31 May 2013, CCAMLR-SM-II/04.

A proposal for the establishment of a Ross Sea Region Marine Protected Area, Delegations of New Zealand and the USA, 2 September 2013, CCAMLR-XXXII/27.

Antarctic and Southern Ocean Coalition Key Principles in Designating Marine Protected Areas and Marine Reserves submitted to CCAMLR 21 September 2013, CCAMLRXXXII/BG/16.

CCAMLR Commission Report of the Thirty-Second Meeting of the Commission, OctoberNovember 2013, CCAMLR-XXXII.

CCAMLR Commission Report of the Second Special Meeting of the Commission, July 2013, CCAMLR-SM-II. 
CCAMLR Commission Report of the Thirty-First Meeting of the Commission, OctoberNovember 2012, CCAMLR-XXXI.

CCAMLR Commission Report of the Thirtieth Meeting of the Commission, OctoberNovember 2011, CCAMLR-XXX.

CCAMLR Commission Report of the Twenty-Eight Meeting of the Commission, OctoberNovember 2009, CCAMLR-XXVIII.

CCAMLR Commission Conservation Measure 91-02 Protection of the values of Antarctic Specially Managed and Protected Areas (2012).

CCAMLR Commission Conservation Measure 91-03 Protection of the South Orkney Islands southern shelf (2009).

CCAMLR Commission Conservation Measure 91-04 General framework for the establishment of CCAMLR Marine Protected Areas (2011).

Scientific Committee for the Conservation of Antarctic Marine Living Resources Report of the Thirty-Second Meeting of the Scientific Committee, October 2013, SC-CAMLRXXXII.

Scientific Committee for the Conservation of Antarctic Marine Living Resources Report of the First Intersessional Meeting of the Scientific Committee, July 2013, SC-CAMLR-IMI.

Scientific Committee for the Conservation of Antarctic Marine Living Resources Report of the Thirty-First Meeting of the Scientific Committee, October 2012, SC-CAMLR-XXXI.

Scientific Committee for the Conservation of Antarctic Marine Living Resources Report of the Thirtieth Meeting of the Scientific Committee, October 2011, SC-CAMLR-XXX.

Scientific Committee for the Conservation of Antarctic Marine Living Resources Report of the Twenty-Seventh Meeting of the Scientific Committee, October 2008, SC-CAMLRXXVII.

2 Antarctic Treaty Consultative Meeting Documents

ATCM Final Report of the Thirty-Second Antarctic Treaty Consultative Meeting (Baltimore, April 2009).

CCAMLR in the Antarctic Treaty System (New Zealand, ATCM 29, 2006).

Designation of Marine Protected Areas within the Antarctic Treaty Area (ASOC, ATCM 31, 2008).

Marine Protected Areas in the Southern Ocean: A focus on CCAMLR (IUCN, ATCM 29, 2006).

Marine spatial protection and management under the Antarctic Treaty System: new opportunities for implementation and coordination (IUCN, ATCM 34, 2011).

Protecting the Antarctic Marine Ecosystem: A Role for the ATCM (ASOC, ATCM 32, 2009).

Report of the Joint CEP/SC-CAMLR Workshop (CEP 11, April 2009).

Summary of the work of the CEP on Marine Protected Areas (CEP, September 2013). 
The work of CCAMLR on Marine Protected Areas (CCAMLR, ATCM 29, 2006).

Using ASMAs and ASPAs when necessary to complement CCAMLR MPAs (IUCN, ATCM $35,2012)$.

$3 \quad$ OSPAR

OSPAR Commission OSPAR Decision 2012/2 on the establishment of the Charlie-Gibbs South Marine Protected Area (2010).

OSPAR Commission OSPAR Decision 2010/6 on the establishment of the MAR North of the Azores High Seas Marine Protected Area (2010).

OSPAR Commission OSPAR Decision 2012/1 on the establishment of the Charlie-Gibbs North High Seas Marine Protected Area (2012).

OSPAR Commission OSPAR Recommendation 2003/3 on a Network of Marine Protected Areas (2003).

OSPAR Commission OSPAR Recommendation 2010/2 on amending Recommendation 2003/3 on a network of Marine Protected Areas (2010).

OSPAR Commission OSPAR Recommendation 2010/12 on the Management of the Milne Seamount Complex Marine Protected Area (2010).

OSPAR Commission OSPAR Recommendation 2010/13 on the Management of the CharlieGibbs South Marine Protected Area (2010).

OSPAR Commission OSPAR Recommendation 2010/17 on the Management of the MAR North of the Azores High Seas Marine Protected Area (2010).

OSPAR Commission OSPAR Recommendation 2012/1 on the Management of the CharlieGibbs North High Seas Marine Protected Area (2012).

OSPAR Commission 2012 Status Report on the OSPAR Network of Marine Protected Areas (2013).

OSPAR Commission Memorandum of Understanding between the North East Atlantic Fisheries Commission (NEAFC) and the OSPAR Commission (2008).

$4 \quad N E A F C$

NEAFC Report of the $32^{\text {nd }}$ Annual Meeting of the North-East Atlantic Fisheries Commission (11-15 November 2013).

NEAFC Report of the $31^{\text {st }}$ Annual Meeting of the North-East Atlantic Fisheries Commission (12-16 November 2012).

NEAFC Report of the $30^{\text {th }}$ Annual Meeting of the North-East Atlantic Fisheries Commission (Volume I, 7-11 November 2011).

NEAFC Report of the $28^{\text {th }}$ Annual Meeting of the North-East Atlantic Fisheries Commission (9-13 November 2009). 
General advice on Vulnerable deep-water habitats in the NEAFC Regulatory Area (ICES Advice, Special Request, June 2013).

\section{Texts}

Churchill, R.R. and Lowe, A.V. The Law of the Sea (3rd ed, Manchester University Press, Manchester, 1999).

Claudet, Joachim (ed) Marine Protected Areas: A Multidisciplinary Approach (Cambridge University Press, Cambridge, 2011).

Lodge, Michael W "Developing a Model for Improved Governance by Regional Fisheries Management Organisations" in David Vidas (ed) Law, Technology and Science for Oceans in Globalisation (Martinus Nijhoff Publishers, Leiden, 2010).

Meltzer, Evelyne The Quest for Sustainable International Fisheries: regional efforts to implement the 1995 United Nations Fish Stock Agreement (National Research Council of Canada, Ottawa, 2009).

Mossop, Joanna "High Seas Marine Protected Areas: Unfulfilled Promise or Impossible Premise?" in A Costi and Y-L Sage (eds) Environmental Law in the Pacific: International and Comparative Perspectives (New Zealand Association of Comparative Law and Association de Legislation Comparee des Pays du Pacifique, Wellington, 2005).

Rayfuse, Rosemary “The Anthropocene, Autopoiesis and the Disingenuousness of the Genuine Link: Addressing Enforcement Gaps in the Legal Regime for Areas Beyond National Jurisdiction" in Erik J Molenaar and Alex Oude Elferink (eds) The International Legal Regime of Areas Beyond National Jurisdiction: Current and Future Developments (Martinus Nijhoff Publishers, Leiden, 2010).

Rayfuse, Rosemary Non-Flag State Enforcement in High Seas Fisheries (Martinus Nijhoff Publishers, Leiden, 2004).

Rothwell, Donald and Stephens, Tim The International Law of the Sea (Hart Publishing, Portland, Oregon, 2010).

Scott, Karen "Marine Protected Areas in the Southern Ocean" in Erik J Molenaar, Alex G Oude Elferink and Donald R. Rothwell (eds) The Law of the Sea and the Polar Regions: Interactions between Global and Regional Regimes (Martinus Nijhoff Publishers, Leiden, 2013).

Tanaka, Yoshifumi The International Law of the Sea (Cambridge University Press, Cambridge, 2012).

Tanaka, Yoshifumi A Dual Approach to Ocean Governance: the cases of zonal and integrated management in international law of the sea (Ashgate Publishing, Farnham, 2008). 


\section{E Articles}

Ardron, Jeff A. and others "The sustainable use and conservation of biodiversity in ABNJ: What can be achieved using existing international agreements?" (2014) 49 Marine Policy 98.

Ban, Natalie and others "Systematic Conservation Planning: A Better Recipe for Managing the High Seas for Biodiversity Conservation and Sustainable Use" (2014) 7(1) Conservation Letters 41.

Bastmeijer, Kees, and van Hengel, Steven "The role of the protected area concept in protecting the world's largest natural reserve: Antarctica" (2009) 5(1) Utrecht Law Review 61.

Brooks, Cassandra M. "Competing values on the Antarctic high seas: CCAMLR and the challenge of marine-protected areas" (2013) 3(2) The Polar Journal 277.

Clark, Beth C. and Hemmings, Alan D. "Problems and Prospects for the Conservation on the Conservation of Antarctic Marine Living Resources Twenty Years On” (2001) 4(1) Journal of International Wildlife Law \& Policy 47.

Drankier, Petra "Marine Protected Areas in Areas beyond National Jurisdiction" (2012) 27 IJMCL 291.

Englender, Dorota and others "Cooperation and compliance control in areas beyond national jurisdiction" (2014) 49 Marine Policy 186.

Fabra, Adriana and Gascon, Virginia "The Convention on the Conservation of Antarctic Marine Living Resources (CCAMLR) and the Ecosystem Approach" (2008) 23 IJMCL 567.

Freestone, David and others "Can existing institutions protect biodiversity in areas beyond national jurisdiction? Experiences from two on-going processes" (2014) 49 Marine Policy 167.

Freestone, David and Morrison, Kate "The Sargasso Sea: Seeking to Protect the Sargasso Sea” (2012) 27 IJMCL 647.

Gjerde, Kristina M. "Challenges to Protecting the Marine Environment beyond National Jurisdiction" (2012) 27 IJMCL 839.

Gjerde, Kristina and Rulska-Domino, Anna "Marine Protected Areas beyond National Jurisdiction: Some Practical Perspectives for Moving Ahead" (2012) 27 IJMCL 351.

Kaye, Stuart "Implementing high seas biodiversity conservation: global geopolitical considerations" (2004) 28(3) Marine Policy 221.

Kvalvik, Ingrid "Managing institutional overlap in the protection of marine ecosystems on the high seas. The case of the North East Atlantic" (2012) 56 Ocean \& Coastal Management 35.

Matz-Luck, Nele and Fuchs, Johannes "The impact of OSPAR on protected area management beyond national jurisdiction: Effective regional cooperation or a network of paper parks?” (2014) 49 Marine Policy 155. 
Miller, Denzil, Sabourenkov, Eugene, and Ramm, David "Managing Antarctic Marine Living Resources: The CCAMLR Approach" (2004) 19(3) IJMCL 317.

Miller, Denzil, Slicer, Natasha, and Hanich, Quentin "Monitoring, control and surveillance of protected areas and specially managed areas in the marine domain" (2013) 39(1) Marine Policy 64.

Molenaar, Erik J. and Oude Elferink, Alex G. "Marine protected areas in areas beyond national jurisdiction: The pioneering efforts under the OSPAR Convention" (2009) 5 Utrecht Law Review 5.

Molenaar, Erik J "Managing Biodiversity in Areas Beyond National Jurisdiction” (2007) 22(1) IJMCL 89.

Monterio, Sara, Vazquez, Xavier, and Long, Ronan "Improving fishery law enforcement in marine protected areas" (2010) 1(1) Aegean Review of the Law of the Sea and Maritime Law 95.

Nordtvedt Reeve, Lora, Rulska-Domino, Anna and M. Gjerde, Kristina "The Future of High Seas Marine Protected Areas" (2012) 26 Ocean Yearbook 265.

O'Leary, B.C. and others "The first network of marine protected areas (MPAs) in the high seas: The process, the challenges and where next" (2012) 36 Marine Policy 598.

Rayfuse, Rosemary "Precaution and the Protection of Marine Biodiversity in Areas beyond National Jurisdiction" (2012) 27 IJMCL 773.

Rayfuse, Rosemary and Warner, Robin "Securing a Sustainable Future for the Oceans Beyond National Jurisdiction: The Legal Basis for an Integrated Cross-Sectoral Regime for High Seas Governance for the 21st Century" (2008) 23 IJMCL 399.

Ribeiro, Marta Chantal "The 'Rainbow': The First National Marine Protected Are Proposed Under the High Seas" (2010) 25 IJMCL 183.

Rochette, Julien and others "The regional approach to the conservation and sustainable use of marine biodiversity in areas beyond national jurisdiction" (2014) 49 Marine Policy 109.

Salpin, Charlotte and Germani, Valentina "Marine Protected Areas Beyond Areas of National Jurisdiction: What's Mine is Mine and What You Think is Yours is also Mine" (2010) 19(2) RECIEL 174.

Sanchez, Rodolfo Andres, and McIvor, Evan "The Antarctic Committee for Environmental Protection: past, present and future" (2007) 43 Polar Record 239.

Schiffman, Howard S. "CCAMLR Fisheries: Challenges to Effective Conservation and Management" (2009) 12(3) Journal of International Wildlife \& Policy 180.

Scott, Karen "Conservation on the High Seas: Developing the Concept of the High Seas Marine Protected Areas" (2012) 27 IJMCL 849.

Scovazzi, Tullio "Marine Protected Areas on the High Seas: Some Legal and Policy Considerations" (2004) 19(1) IJMCL 1.

Spalding, Mark and others "Protecting Marine Spaces: Global Targets and Changing Approaches” (2013) 27 Ocean Yearbook 213. 
Tanaka, Yoshifumi "Reflections on High Seas Marine Protected Areas: A Comparative Analysis of the Mediterranean and the North-East Atlantic Models" (2012) 81 Nordic Journal of International Law 295.

Tanaka, Yoshifumi "Zonal and Integrated Management Approaches to Ocean Governance: Reflections on a Dual Approach in International Law of the Sea" (2004) 19(4) IJMCL 483.

Warner, Robin M. "Conserving marine biodiversity in areas beyond national jurisdiction: coevolution and interaction with the law of the sea" (2014) 1 Frontiers in Marine Science 1.

\section{F Reports}

Conserving Marine Biodiversity: Addressing Existing Commitments and Designing Next Steps for Action (The Pew Environment Group, April 2013).

Dotinga, Harm and Molenaar, Erik J The Mid-Atlantic Ridge: A Case Study on the Conservation and Sustainable Use of Marine Biodiversity in Areas beyond National Jurisdiction (IUCN, Switzerland, 2008).

Druel, Elisabeth and others Governance of marine biodiversity in areas beyond national jurisdiction at the regional level: filling the gaps and strengthening the framework action (Institute for Sustainable Development and International Relations, 2012).

Establishing Resilient Marine Protected Areas- Making it Happen (IUCN World Commission on Protected Areas, 2008).

Grant, Susie and others Bioregionalisation of the Southern Ocean: Report of Experts Workshop (WWF Australia and the Antarctic Climate and Ecosystems Cooperative Research Centre, Hobart, 2006).

High Seas Marine Protected Areas (Parks Volume 15(3), IUCN, 2005).

International Seminar on Conservation and Sustainable Use of Marine Biodiversity beyond National Jurisdiction: Summary Report (IUCN and German Federal Agency for Nature Conservation, Bonn, 2011). [Bonn report].

Recommended Best Practices for Regional Fisheries Management Organizations (The Royal Institute of International Affairs, Chatham House, London, 2007).

Regulatory and Governance Gaps in the International Regime for the Conservation and Sustainable Use of Marine Biodiversity in Areas beyond National Jurisdiction (IUCN Marine and Law Policy Series No 1, 2008).

\section{G Other Sources}

"A proposal for a representative system of Marine Protected Areas in the East Antarctic planning domain" Australia Department of the Environment, Antarctic Division $<$ www.antarctica.gov.au>.

"Area Protection and Management/Monuments" Secretariat of the Antarctic Treaty $<$ www.ats.aq $>$. 
Cressey, Daniel "Disappointment as Antarctic protection bid fails" (1 November 2013) nature international weekly journal of science $<w w w . n a t u r e . c o m>$.

“Double blow for Japan's whalers” TheGuardian (online ed, 22 June 2005).

European Commission "Regional fisheries management organisations (RFMOs)"

$<$ www.ec.europa.eu>.

Kock, Karl-Hermann (ed) "Understanding CCAMLR's Approach to Management” (2000).

IUCN "When is a Marine Protected Area really a Marine Protected Area" (8 September 2012) <www.iucn.org>.

Milman, Oliver "Delegates frustrated as talks to create huge Antarctic marine reserves fail" TheGuardian (online ed, 1 November 2013).

Morton, Jamie "NZ marine reserve bid blocked" The New Zealand Herald (online ed, 1 November 2013).

NIWA "Antarctic Toothfish Fishery in the Ross Sea" <www.niwa.co.nz>.

OSPAR Commission "The North East Atlantic" <www.ospar.org>.

"Ross Sea region Marine Protected Area: Revised Proposal” New Zealand Ministry of Foreign Affairs and Trade <www.mfat.govt.nz/ross-sea-mpa $>$.

Sargasso Sea Commission "Northwest Atlantic Fisheries Organization" $<$ www.sargassoalliance.org $>$.

The European Free Trade Association "The EFTA States" <www.efta.int>.

"Toothfish fisheries" CCAMLR <www.ccamlr.org>.

Trevett, Claire "McCully 'optimistic but not confident' over Ross Sea deal" The New Zealand Herald (online ed, 22 October 2013).

University of Canterbury "Ross Sea protected area proposal fail but not all lost" (press release, 17 July 2013) accessed at $<$ www.scoop.co.nz $>$.

"Why the Ross Sea region" New Zealand Ministry of Foreign Affairs and Trade $<$ www.mfat.govt.nz/ross-sea-mpa $>$. 